\title{
Busara
}

Busara Blue Paper Series

Primed, but not engaged:

the poor performance of

self-efficacy primes in

promoting civic engagement,

in a laboratory experiment in

Uganda

No. 001

Tom Wein, Nicholas Owsley, Alice Escande, Lornah Wahome, Pauline Wanjeri,

Charity Okaba, Joseph Kimani, Mathius Mwesige, Douglas Wanja 


\title{
Busara
}

\section{Primed, but not engaged: the poor performance of self-efficacy primes in promoting civic engagement, in a laboratory experiment in Uganda}

Tom Wein ${ }^{1}$, Nicholas Owsley², Alice Escande ${ }^{3}$, Lornah Wahome ${ }^{3}$, Pauline Wanjeri ${ }^{3}$,

Charity Okaba ${ }^{3}$, Joseph Kimani ${ }^{3}$, Mathius Mwesige ${ }^{4}$, Douglas Wanja ${ }^{4}$

\author{
Author Affiliations: \\ [1] The Dignity Project; formerly of the Busara Center for Behavioral Economics. \\ [2] The Busara Center for Behavioral Economics. Corresponding author: \\ nicholas.owsley@busaracenter.org \\ [3] The Busara Center for Behavioral Economics \\ ${ }^{[4]}$ Formerly of the Busara Center for Behavioral Economics
}

Non-Author Contributions: We are indebted to all our participants. We are grateful to the full team of data collectors who supported this work: Byakagaha Moses, Julius Mwesigwa, Kicoconco Judith, Muhwezi Derrick, Natukunda Bosco, Steven Sebulime, Nantale Rebecca, Judith Businge, Geofrey Mutole, and George Otuna. We thank AFIEGO, our CSO partner, and especially Diana Nabiruma for their hard slow work furthering civic engagement and prompting responsive governments. Finally, we thank Hrag Vosgerichian and Sami Horn for assistance with the paper.

Conflicts of Interest: There are no Conflicts of Interest to declare for this study

Open Science: All study materials can be found here:

IRB: This design was approved by Makerere University's Research Ethics Committee (MAKSS REC 11.17.100), and from the Uganda National Council on Science and Technology (HS 2350).

Funding: The Funding was provided by a large philanthropic fund that would prefer to remain undisclosed at this time.

The Busara Blue Paper Series is a collection of working papers on topics relevant to experimental and behavioral economics in the global South. All papers comply with Busara's Open Science and research ethics policies, have IRB approval, and all study materials and data are to be published on the Open Science Framework www.osf.io. Papers are circulated for discussion and comment feedback on the paper directly to the corresponding author is welcomed. 


\section{Primed, but not engaged: the poor performance of self-efficacy primes in promoting civic engagement, in a laboratory experiment in Uganda}

\section{Abstract}

Civic engagement is considered an important element of a healthy polity. Yet, many attempts to induce it fail, and experimental evidence on 'what works' to induce it is limited. Further, most experimental studies in this area of research focus on self-reported or low-cost proxy behavior outcomes. This paper describes a laboratory experiment with 809 participants to measure the impact of short behaviorally-informed messages on civic engagement in Uganda. We randomly assign participants to three treatment audio messages, applying different self-efficacy enhancing techniques, and one control audio, and measure their effect on two primary components of civic engagement: a lab measure of attention to political and pre-political information, and a real-world activity measure: attendance at a community meeting. We find that short audio messages can prompt people to pay more attention to pre-political information, but do not encourage overall civic engagement behavior, and some treatments produce a significant negative effect on our measures of engagement. We also find that a rights-focused message, closely modelling current civil society practice, does not generate increased civic engagement. We conclude that one-off behaviorally informed audio messages are insufficient to generate civic engagement in this context.

JEL Codes: D72; D91; P48

Key Words: civic engagement; political behavior; laboratory experiments; behavioral interventions; primes 


\section{Introduction}

Civic engagement is valuable (Putnam, 1993). Sustained public participation in governance has been shown in a meta-analysis to increase (a) the construction of citizenship, (b) the strengthening of practices of participation, (c) the strengthening of responsive and accountable states, and (d) the development of inclusive and cohesive societies (Gaventa \& Barrett, 2012). This is also true in the Global South: Booth \& Cammack (2013) provide case studies of statecitizen cooperation greatly improving services from Malawi, Niger, Uganda and Rwanda. Moreover, given certain conditions, public participation in governance can be induced (Mansuri \& Rao, 2013). If it is possible to "make politics work for development", we should (Khemani et al, 2016).

There is an extensive literature on encouraging political engagement through voting, much of it drawn from the US (Gerber et al, 2008; see Dunning et al, 2018 for summaries of non-US research). In more recent years, political scientists have sought to better understand political behavior in countries without consolidated democratic institutions (Gehlbach et al, 2016), where leaders have become increasingly good at manipulating election results (Cheeseman \& Klaas, 2018) and where more meaningful political and civic engagement often occurs outside of formal democratic institutions, including through smaller civil society organizations (Boulding, 2010). In these settings, inducing non-electoral engagement may be particularly important. Furthermore, identifying low-cost and tractable methods for inducing engagement may be especially valuable for CSOs and other small civic actors.

Yet many attempts to induce engagement in non-democracies fail (Mansuri \& Rao, 2013). Commonly used information treatments rarely work (Dunning et al, 2018; Chowdhury et al, 2018), more elaborate training programs achieve limited success (Soboleva, 2019), and largescale government-sanctioned interventions show limited effect on citizen engagement (Raffler et al, 2018). These interventions are also arguably outside of the scope of resource-constrained CSO activities. There is therefore limited experimental evidence on the effects of low-cost portable interventions on civic engagement in countries with weak democratic institutions.

We investigate whether behavioral science can suggest more effective low-cost interventions. Specifically, we focus on behaviorally informed interventions to increase self-efficacy as a mechanism to increase engagement. Self-efficacy, and the related concept of political efficacy, 
has long been considered an important input to political engagement (Solhaug, 2006; Fox \& Lawless, 2011; Valentino et al, 2009; Gottlieb, 2016; Grossman et al., 2017). Self-efficacy specifically has been linked to higher engagement with authorities and improved collective action (Caprara et al., 2009; Anderson, 2010), and generally higher involvement in public matters (Fioramonti, 2012). Furthermore, self-efficacy can be manipulated independently of structural political constraints (McKelway, 2019; McClendon \& Riedl, 2015), making it an appealing mechanism to target using low-cost interventions in settings with less functional formal democratic institutions. This study therefore expands on recent experimental studies that target self-efficacy to increase civic engagement in East Africa (Horn \& Keyman, 2016; McClendon \& Riedl, 2015) and elsewhere (Soboleva, 2019).

We conduct a laboratory experiment in Kampala and Kabale, Uganda, in April-July $2018^{1}$ to test three interventions applying different self-efficacy enhancing techniques: rights information, focus on past success, and a story demonstrating civic engagement. The first of these closely models current civil society practice. The second and third of these were derived from a taxonomy of behavioral change techniques (Michie et al, 2013) and previous research on the relationship between self-efficacy and civic engagement (Horn \& Keyman, 2016; McClendon \& Riedl, 2015); we finally applied a forecasting and piloting exercise (DellaVigna $\&$ Pope, 2018) to determine the final pair of self-efficacy enhancing interventions. We examine whether these treatments induce components of political engagement, defined as both political activity (attending a community meeting) and political attention (recall of 'background' or nonsalient political information). We further examine whether they induce secondary components of 'civic engagement', in this case expressing willingness to attend a community meeting, and 'pre-political' attention.

None of our treatments increase civic engagement. Listening to rights information and to a story demonstrating civic engagement reduce attendance to a community meeting. Though exploratory qualitative evidence tentatively suggests that there may be a substitution to alternative and unmeasured forms of political activity, we see no clear evidence of increased engagement from these treatments. Listening to a story demonstrating civic engagement led to the lowest scores on political attention out of all groups. However, listening to the 'focus on

\footnotetext{
${ }^{1}$ Data and code for replicating the results of this paper are stored at: https://osf.io/ynzfe/?view_only=bbf0054a29fa49c3b9ce9ba7ad301148.
} 
past success' intervention and to the 'rights information' intervention increases scores on the pre-political attention measure relative to a control group. Self-efficacy remains unchanged with any intervention relative to the control group.

We conclude that overcoming structural barriers to political engagement is difficult. Psychological nudges can help people pay attention, but don't appear to induce political engagement, and specifically not political activity in a setting with structural constraints. We additionally conclude that activists may be overusing rights language. A treatment that closely modelled existing civil society practice performed no better than our control recording describing a wooden table.

We provide several novel contributions to the literature on inducing civic engagement in unconsolidated democracies, and to the literature on self-efficacy and political behavior change. First, we conduct one of the first experimental studies to test the effect of self-efficacy promoting interventions on civic engagement in Africa, contributing to an active debate on what encourages civic engagement in this setting (McClendon \& Riedl, 2015; Young, 2017). Second, we provide some of the first evidence on the effectiveness of a set of low-cost audiobased interventions (designed to be usable by CSOs and other civic actors) on self-efficacy and civic engagement. Third, we apply a new, more precise definition of civic engagement and operationalize its components into experimental outcomes. Fourth, we design a novel set of observed behavioral measures of 'civic attention' and 'civic activity'. Finally, we apply a new structured approach to treatment selection that combines a taxonomy of behavioral change techniques and the use of literature with a forecasting exercise and piloting.

In the following sections, we discuss the literature on inducing and defining civic engagement in Uganda (Section 2), describe our methods (3), provide results (4), and discuss their implications (5). 


\section{Literature review}

\subsection{Inducing civic engagement}

Civic engagement is malleable. In a laboratory experiment, McClendon \& Riedl (2015) show that self-affirmation messages encourage participation in a political text message campaign in Kenya. Young (2017) finds that anger appeals significantly outperform enthusiasm appeals in promoting participation in pro-opposition discussion groups in Zimbabwe. In a series of larger RCTs, Grossman et al (2018) show that providing a new texting platform can temporarily increase citizen communication in Uganda, though this does not lead to improved services (see also, Grossman et al, 2017; Grossman et al, 2014). An edutainment film and mass text messages both persuaded participants to text in to report corruption in Nigeria (Blair et al, 2017).

However, large scale trials of these ideas have often failed to demonstrate impact. Raffler et al (2018) show that an information and mobilisation treatment does not lead to greater citizen monitoring, and had no effect on service delivery by Ugandan health clinics (convincingly contradicting earlier evidence from Björkmann \& Svensson, 2009). Buntaine et al (2018) show that an SMS campaign has no impact on participation, also in Uganda. Banerjee et al (2008) show that providing information, training community members in a new testing tool, and training and organizing volunteers to hold remedial reading camps for illiterate children all fail to increase citizen participation in Indian schooling. Reviewing the 178 tech-based projects from the Making All Voices Count initiative, McGee et al (2018) offer 14 messages of caution about the effects of such projects (c.f. Peixoto \& Sifry, 2017). Chowdhury et al's meta-analysis (2018) has shown that privately communicated information fails to alter voting behavior across six studies in developing countries, though publicly communicated does seem to have an impact (Pandey et al, 2009; Reinikka \& Svensson, 2011; Chowdhury et al, 2018).

Can behavioral science suggest more effective (and more cost-effective) interventions? There are entire literatures dedicated to showing that psychologically-informed primes can yield changes in behavior (Kahneman, 2011). For example, identity primes can increase or decrease cheating behaviour (Cohn et al, 2015); primes can also affect political identity and preferences for redistribution (Chang et al, 2016). Primes and short scripts also have the benefit of being 
low-cost and portable, by definition. However, there is little evidence of the effect of such primes and short audios on civic engagement.

There is good reason to think that self-efficacy focused primes could be effective here. According to Wood and Bandura (1989), "self-efficacy refers to beliefs in one's capabilities to mobilize the motivation, cognitive resources, and courses of action needed to meet given situational demands." There is a large body of evidence showing that self-efficacy as a construct is predictive of a range of broadly positive behaviors and outcomes, including learning (Salami, 2010) and capacity to overcome health challenges (Marks et al, 2005). We noted earlier that self-efficacy is one concept drawn from psychology that has shown promise in affecting behaviours related to political engagement (Solhaug, 2006; Fox \& Lawless, 2011; Valentino et al, 2009; Gottlieb, 2016; Grossman et al., 2017). McClendon \& Riedl (2015) have shown both that it can be manipulated through low-cost audio primes, and that it can change political behaviours in East Africa.

There is also some reason to believe that self-efficacy interventions may be a more ethical category of intervention, given the potential dangers of political engagement in weakly democratic states. This is because self-efficacy interventions simply increase people's capabilities to engage politically, rather than directly motivating them to do so. For these reasons - evidence of potential effectiveness, and ethical considerations - we select self-efficacy focused treatments.

\subsection{Defining civic engagement}

Civic engagement is vague. From Putnam (1993) onwards, there have been a host of studies of it, yet there is a clear lack of consensus about the term. A host of definitions have been offered (Adler \& Goggin, 2005). Berger (2009) calls it a "catch-all term for almost anything that citizens might happen to do together or alone" and asserts that "the word's combination of benevolence and ambiguity contributed to civic engagement's broad appeal yet also contributed to our current confusion." It fails many of the tests of conceptual 'goodness' (Gerring, 1999). This vagueness brings steep costs: we talk past one another, and struggle to operationalize such a broad concept. By pinning it down, we can speak and act with much greater clarity. 
Berger (2009) identifies three separate concepts that have been subsumed into civic engagement: political engagement, social engagement and moral engagement. Political engagement is engagement with power (Dahl, 1963). Social and moral engagement are valuable in themselves, but they are also important precursors of political engagement - they are 'pre-political' (Ekman \& Amna, 2012). (This is very similar to arguments about the political value of social capital [Putnam, 1993; Teorell, 2003]). One useful way of conceiving this is the idea of the episodically engaged 'monitorial citizen' (Amna \& Ekman, 2014). These are citizens who are "interested in politics, informed, skilled, and have political efficacy beliefs. For the time being, many of them chose not to take part in politics but they are on "standby"" (Ekman \& Amna, 2012). They direct attention towards politics, and stand ready to direct activity as soon as it is required.

Engagement we define as requiring both activity and attention (Berger, 2009). In this, civic engagement differs from political participation, which requires only an episodic political action.

Figure 1 illustrates these overlapping concepts, with moral engagement and social engagement making up pre-political engagement, political engagement requiring both political activity and political attention, and an intermediary concept of monitorial citizenship, which combines prepolitical engagement with political attention, but excludes political action.

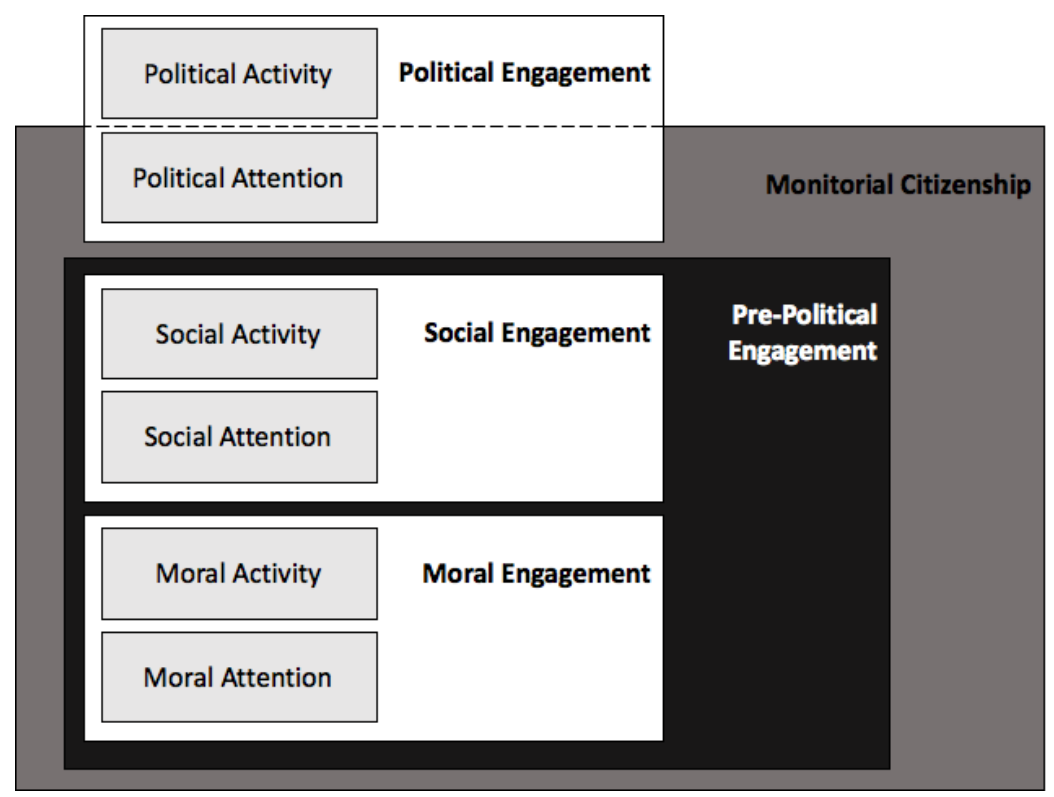

Figure 1. Components of civic engagement. 
Given this definition of civic engagement, we attempt to measure 'attention' and 'activity' separately. No study to date has attempted to measure these components as defined above. Most studies that attempt to manipulate political engagement in developing countries have taken as their outcome measure a comparatively low-cost political behavior, such as sending a text message (Grossman et al, 2018), recording an audio message (McClendon \& Riedl, 2015), attending a short information session (Horn \& Keyman, 2016), or wearing a wristband (Young, 2019). Most similar studies in the developed world have focused on voting as the primary outcome (Gerber et al, 2008; see also Kalla \& Broockman, 2017) while numerous efforts use only self-reported rather than observed measures (Berger, 2009). We identified only one experiment that measured something akin to attention: Preece (2016) has shown with a US sample that providing feedback to boost self-efficacy can stimulate political interest, as measured by a single self-reported item. We therefore develop a unique measure of political and pre-political attention, and combine this with a novel measure of political activity.

\subsection{Civic engagement in Uganda}

The current Ugandan government is an often-unresponsive hybrid regime that seeks to control many aspects of civic engagement (Tripp, 2010). In a 2008 survey, just 38\% of Ugandans said that elected representatives "often" or "always" "try their best to listen to what people like you have to say" (Bratton, 2012). 58\% of respondents to a 2017 AfroBarometer survey said that opposition political parties have less freedom to act than in the past, and $71 \%$ said they fear political intimidation or violence at least "a little bit". There is a gap of 34 points between the perceived and desired amount of democracy - up from just a 5 point gap in 2000 (Kibirige, 2018).

Ugandans may have good reason to want to improve services. For instance, just $7 \%$ of respondents had access to piped water, with the mean walk to a water source in the dry season over a kilometer and the mean wait at the water source being 42 minutes (Kabunga et al, 2016). Many paid additional fees for this service (Kabunga et al, 2016) - and 4 in 10 say that their access to water is getting worse (Twaweza, 2018a). 7 out of 10 Ugandans responding to a recent Sauti za Wananchi poll say addressing inequality is urgent, but just 3 out of 10 say national leaders are treating it as urgent (Twaweza, 2018b). 
Ugandan citizens do have some opportunities to be civically engaged (Devas \& Grant, 2003). A majority of respondents to a Sauti za Wananchi poll had sought information through personally visiting the offices of public service providers (Twaweza, 2018c). 8 out of 10 say that criticising government leaders is a good thing, and $68 \%$ feel free to criticise a village or street chairman (though only 44\% would feel free to criticise the president) (Twaweza, 2018c).

One important means of civic engagement is barazas, or community meetings. The Ugandan government has run a formalised program of such meetings since 2009 , which explicitly aims to "enhance public involvement in holding the government accountable for service delivery in relation to the resources spent" (Van Campenhout et al, 2018), but they have a much longer history as a mechanism of communication between authorities and other people across East Africa (Haugerud, 1997). They are frequently organised by civil society organisations (CSOs) across Uganda (Van Campenhout et al, 2018). Many stakeholders offered examples of barazas having had impact in a qualitative study (Van Campenhout et al, 2018), but they are not widely publicised; Kabunga et al (2016) found that just $10 \%$ of respondents were aware of any public service-related meetings in their area.

There have now been many efforts in Uganda to encourage people to be politically or prepolitically engaged (Van Campenhout et al, 2018; Grossman et al, 2018; Grossman et al, 2017; Grossman et al, 2014; Raffler et al, 2018; Bjorkmann \& Svensson, 2009; Buntaine et al, 2018; Reinikka \& Svensson, 2011; Chowdhury et al, 2018). Golooba-Mutebi has charted the longer history of such efforts in Uganda, arguing that though public meetings as consultative fora are widely recognised platforms for engagement, their use has declined steadily in recent years (Golooba-Mutebi, 2004).

Uganda therefore offers several advantages as a location for this study. First, it is the site of other similar studies, which should enhance comparability of results. Second, it is a place where non-electoral political engagement is of particular interest to scholars (Cheeseman \& Klaas, 2018) and where greater democracy is demanded by citizens (Kibirige, 2018). Third, there is a history of non-electoral engagement, specifically through community meetings (Busara, 2017), but where pre-existing engagement is variable and in need of stimulation (Golooba-Mutebi, 2004), allowing an opportunity for outcomes in this study to be both moveable and policyrelevant. 


\section{Methods}

We conducted a laboratory experiment with four treatment arms randomly assigned at the individual level, and outcome measures recorded both in the laboratory and at a real community meeting held several days after the laboratory sessions. ${ }^{2}$ Given this additional attendance measure at the community meeting, this study could also be classified as an 'extra-laboratory' study (Charness, Gneezy \& Kuhn, 2013) or a 'lab-in-the-field' study.

\subsection{Sampling}

The study took place in two locations in Uganda: Kampala and Kabale. Kampala was chosen because it is the capital city and the largest urban center in Uganda, comprising a significant portion of Uganda's urban population. Kabale, in the South-West of Uganda, was chosen due to the rural social and economic context, relative population density and a relatively high civil society organization presence. In this sense, each represents different but highly relevant segments of Uganda's active polity.

Participants in Kampala were drawn from Busara's subject database, which covers the Kifumbira and Kamwokya areas. Participants in Kabale were recruited from three villages: Igabiro, Nyakiharo and Rwamukunde. All subjects in both locations were between the ages of 18 and 60, and both areas and individual sampling targeted lower and lower-middle income individuals. At recruitment, subjects' demographic information was collected and they provided consent to be contacted to participate in future social science studies. The exact nature of the study was not disclosed at this time ${ }^{3}$. Participants were then invited to participate in the lab study and called in a day or two before their assigned session. In Kampala, sessions ran in the laboratory from 30th of April to June 5th. In Kabale, sessions ran from June 11th to July 19th.

\footnotetext{
2 This design was approved by Makerere University's Research Ethics Committee (MAKSS REC 11.17.100), and from the Uganda National Council on Science and Technology (HS 2350).

Further, all data and materials for this project can be found on OSF here: https://osf.io/ynzfe/?view_only=bbf0054a29fa49c3b9ce9ba7ad301148

${ }^{3}$ Demographic data was not collected for 69 respondents from Kampala due problems with the recruitment survey in the initial stages of recruitment. Further, an additional 37 respondents' demographic data could not be linked to their outcomes due to a failure in internet network during identification. In a post-hoc call survey, the team successfully acquired gender data for 104 out of the 106 missing values. These missing data are 'prior' to and exogenous to treatment assignment.
} 
The total sample for the study is 808 participants. Power calculations, assuming a significance level of 0.95 , balanced random assignment at the individual level, and without any additional covariates, determine that the study is powered to detect an effect size of 0.249 standard deviations (Cohen's d) at the $80 \%$ level.

\subsubsection{Assignment}

Participants were stratified by location and randomly assigned to one of four short behaviorally-informed audio messages. Table 1 shows the summary of demographic variables by treatment group. Groups are balanced across observable characteristics with the exception of the completion of some tertiary education: the Rights Information group includes marginally more tertiary educated respondents than the Control group. This is only marginally significant ${ }^{4}$, and overall, F-tests show that the observables are not predictive of treatment status, indicating that randomization was successful. However, to account for the imbalance in education status, we apply a model with control variables, described in the Empirical Strategy and Results sections.

\footnotetext{
${ }^{4}$ Given the number of comparisons, it is statistically expected that some will be marginally significant even in the event of successful randomization and balanced groups.
} 
Table 1. Summary Statistics and Balance Checks by Treatment Condition

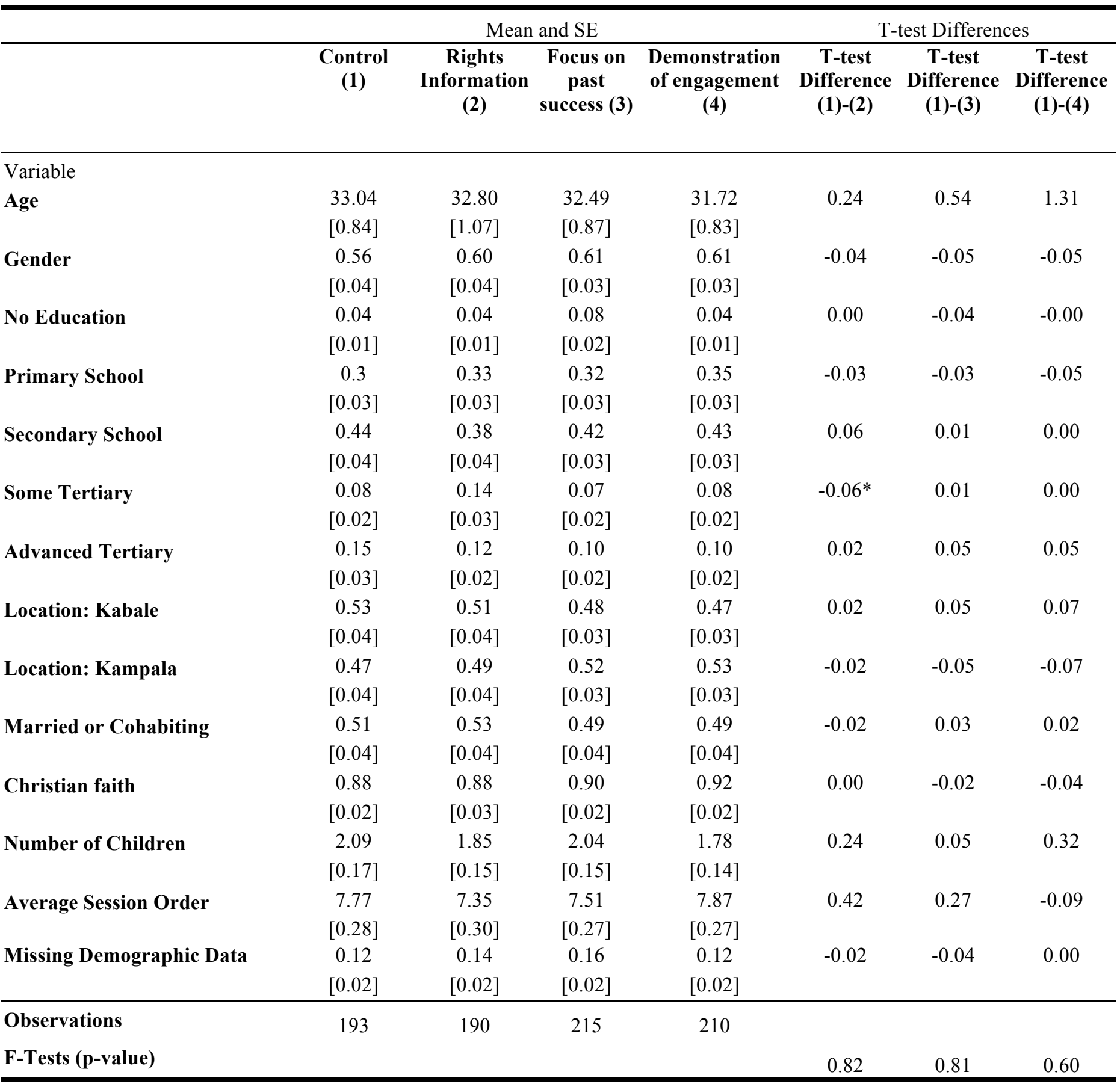

The value displayed for t-tests are the differences in the means across the groups.

***,**, and * indicate significance at the 1,5 , and 10 percent critical level.

The following demographic information is missing for 107 respondents: religion, marital status, education and number of children. Age is missing for 131 respondents. This missing data is due to faults in the baseline survey, is prior to and therefore exogenous to treatment, and is balanced across treatments. 


\subsection{Interventions}

\subsubsection{Final Interventions}

The four treatment conditions are as follows: a control group receiving a 'neutral' audio message, and three treatment groups receiving distinct audio messages designed to encourage self-efficacy: 1) a rights information message, 2) a 'focus on past success' message, and 3) a story demonstrating civic engagement. Each message was constructed to be the same length approximately 5 minutes, within a 20 second margin. Each message also started with the same specific reference to communities engaging leaders, to ensure that control group participants were also exposed to a political 'prime' and that any treatment effect was not the result of discussing political issues but rather due to the difference in content as it related to encouraging self-efficacy. Interventions were specifically designed to be portable and low-cost, such that these or conceptually similar messages could be used by CSOs and other civic actors. The full text of each audio message is contained in Appendix 1, and the core components are summarised in Table 2 below.

\section{Table 2. Description of treatments}

\begin{tabular}{|c|c|}
\hline \multicolumn{2}{|l|}{ Treatments } \\
\hline Control & The control audio described a wooden table in a neutral way. \\
\hline Rights Information & $\begin{array}{l}\text { The rights information intervention emphasized the right to engage } \\
\text { politically. It emphasized the right to demand government transparency, } \\
\text { to speak out against corruption and poor service delivery, to vote, and } \\
\text { for citizens to communicate their needs formally with leaders. It was } \\
\text { developed together with AFIEGO, our Ugandan CSO partner, and } \\
\text { intended to mimic common rights-based messages used by CSOs in } \\
\text { Uganda. }\end{array}$ \\
\hline $\begin{array}{l}\text { Focus on past } \\
\text { success }\end{array}$ & $\begin{array}{l}\text { Participants were invited to recall past successes in persuading someone } \\
\text { prominent in their community or household to do something towards a } \\
\text { social goal. A similar intervention seemed to be effective in promoting } \\
\text { civic engagement-related information-seeking behaviors in previous } \\
\text { studies (Horn \& Keyman, 2016; McClendon \& Riedl, 2015). The script } \\
\text { was derived using materials from these studies. }\end{array}$ \\
\hline
\end{tabular}




\begin{tabular}{|l|l|}
\hline Demonstration of & $\begin{array}{l}\text { Participants heard a short story of a woman (Mama Dorah) successfully } \\
\text { engaging with her community leaders in Uganda. The story was crafted }\end{array}$ \\
in a way that the character engages in a behavior that is relatable, \\
specific and not highly risky, and finds success in doing so. It was \\
adapted from a real news story and follows techniques used in \\
storytelling to successfully change behavior in other fields (Vaughan, \\
Rogers, Singhal and Swalehe, 2000).
\end{tabular}

\subsubsection{Treatment Selection}

We apply a structured and multi-staged process to treatment selection that incorporates substantive theory and treatment selection and refinement procedures.

The appeal to "Rights" was selected as a treatment because it emulates current civil society practice, where practitioners typically see this type of messaging as a means to increase selfefficacy. Its inclusion was motivated by the need to test this existing messaging against a control group, rather than due to strong evidence or theoretical justifications of its effectiveness per se.

The 'focus on past success' and story demonstrating civic engagement treatments were selected through a new, more refined process for treatment selection for such interventions. We began by reviewing the taxonomy of 93 behavioral change techniques (Michie et al, 2013). We focused on techniques that seek to alter participants' sense of 'capability' (Michie et al, 2011) or self-efficacy; the motivation for focusing on self-efficacy primes is discussed in the previous section. We further narrowed the list to focus on those techniques which generate potential changes in self-efficacy and capability as they relate to politics. We corroborate this with the behavioral science literature, the literature on political engagement, and the literature on selfefficacy (Horn \& Keyman, 2016; McClendon \& Riedl, 2015; Vaughan et al, 2000; Dercon, Orkin \& Tafesse, 2014). This process allowed us to outline 9 treatments for which we generated descriptions of primary themes and script outlines. These 9 were then assessed through a forecasting exercise (DellaVigna \& Pope, 2018) with 44 Kenyan and Ugandan research staff from the Busara Center for Behavioral Economics, at both management and field staff level. 
These staff were asked to both evaluate the potential efficacy of each intervention in changing behavior and to rank the interventions. There is mounting evidence that ex-ante average assessments by both research staff and participants can accurately order treatments (DellaVigna $\&$ Pope, 2018). This procedure then generated a list of 5 treatments, which we developed full scripts for, ${ }^{5}$ drawing heavily on the literature on self-efficacy and its relationship with political engagement. These 5 scripts were piloted with participants. Using quantitative results and qualitative debriefs with participants in these pilots, and comparing this with results from the literature discussed above, the final two - 'focus on past success' and a story demonstrating engagement - were selected and revised.

These final treatments are similar to those used by Horn \& Keyman (2016) and McClendon \& Riedl (2015), and therefore have been shown to induce political behaviors in East Africa. Additionally, 'Focusing on past success' is one of the most commonly employed methods for enhancing self-efficacy in other fields (Gist \& Mitchell, 1992; Bandura \& Schunk, 1981). There is also strong evidence that 'demonstrations of action' successfully increases selfefficacy (Gist \& Mitchell, 1992). Both these approaches are listed as viable behavioral change techniques in the taxonomy by Michie et al (2013). There are good theoretical and practical reasons to believe these treatments would move political outcomes.

\subsection{Outcome measures}

The study included two primary outcomes: a measure of political attention derived in the laboratory, and attendance at a real community meeting (political activity). The primary focus is thus 'political engagement', with individual measures to represent each of its components attention and activity.

There are additionally two secondary outcome measures: a measure of pre-political attention derived in the laboratory, and hypothetical attendance at a community meeting, measured by signing up for the meeting. In this case, 'pre-political' attention as a component of 'civic engagement' is treated as less important than 'political attention', while willingness to attend is treated as a 'weaker' observed behavioral measure of political activity.

\footnotetext{
5 The results of this analysis can be found in the study's OSF materials.
} 
Furthermore, we conduct a manipulation check on self-efficacy, using the 10-item Generalized Self-Efficacy Scale (Schwarzer \& Jerusalem, 1995), since we hypothesized that generalized self-efficacy would be the primary mechanism through which the treatments would affect civic engagement.

\subsubsection{Attention Outcomes}

Approximately halfway through the lab session, and post-treatment, participants were invited to take a 'roughly 5-minute' break 'while their payouts were calculated'. During this time, they listened to a set of 15 randomly ordered information clips recorded on audio through zTree (an experimental design software; Fischbacher, 2007) (and while still having their headphones on). Participants were not provided with any primes nor informed of incentives to listen to this information - they were described as 'short informational recordings that we thought you might find interesting for you to listen to as you rest [while the research team prepares payment]'

The information clips contained three types of information, in a randomized order. Five political information clips containing facts about Ugandan national politics, the constitution, elections, national bodies etc. (e.g. Uganda's Constitution was officially adopted in 1995). Five pre-political information clips containing facts about moral or community issues in Uganda (e.g. there is a low uptake of contraceptives by women in Uganda). Finally, five non-political information clips were added as well, to dilute the salience of the political themes (e.g. the adult human body has 206 bones and carries 5 liters of blood). Each piece of information was roughly 18-seconds long in audio and compiled with short pauses between to emulate a newsreel, to both make recall imperfect but also to mimic real-life exposure to similar sets of information.

Immediately after this, participants completed fifteen multiple-choice questions in a random order on zTree (see Appendix 2 for a full list of the questions) - five each on the non-political, political and pre-political information. Each question was incentivised and included one correct answer, aligned with each of the information pieces. The proportion of correct responses out of the 5 political information questions is the primary attention outcome. The proportion of correct responses for the 5 'pre-political' information questions is the secondary attention measure. Each information set and question set was validated during a pilot, to ensure questions 
measured recall rather than prior knowledge. ${ }^{6}$ Both the relative simplicity of each information piece and the short time gap between listening and questionnaire ensured that this primarily measured attention rather than short-term memory capacity. This is a variant on the basic recall measure of attention developed by Robertson et al (1996). Given the need for domain specificity (e.g. attention towards politics) it was not possible to use the Stroop Test or other more common behavioral attention measures. ${ }^{7}$

\subsubsection{Activity Outcomes}

After participants collected their final payout, they were offered the opportunity to participate in a community meeting on how to best address their leaders, where they were told that they would be able to express their opinions and participate in activities. This messaging was used to ensure that it clearly constituted activity, was clearly political, and that it did not narrow the scope to any specific political issue (eg. environmental resource extraction). Further, this form of engagement, community meetings, was chosen because of its local relevance and scope for increased participation (Van Campenhout et al, 2018). Previous qualitative work with similar population groups showed community meetings as a widely accepted civic engagement construct, and one of the primary ways that Ugandans civically engage (Busara, 2017).

Participants then expressed whether or not they were willing to attend this meeting and this was recorded by lab staff. This is the secondary 'activity' outcome measure, as it constitutes a fairly 'weak' self-reported intention form of political activity.

Several days after the final session in each location respectively, participants who previously indicated that they were willing to attend the meeting received an SMS informing them about the date and the venue of the community meeting. ${ }^{8}$ The meeting was conducted in the same

\footnotetext{
${ }^{6}$ Each question was assessed in a questionnaire with pilot respondents from our subject pool with and without having listened to the information clips beforehand. The rate of correct answers when no clips were played was not significantly different from chance-guessing, and the number of correct responses when the clips were played was greater, indicating that it measured attention to the recordings. Ugandan staff also reviewed content closely to ensure that each information piece fell within the desired construct. Finally, Ugandan staff also checked to see if information sets were of similar 'vividness' across categories - similar average correct responses between categories in pilots suggest they were. While vividness differences do not pose a problem for bias, balancing this reduces measurement error.

7 As such this rendition of 'attention' differs slightly from some definitions of it as a psychological construct.

${ }^{8}$ The SMS read: "Hi [Name], the Busara Center invites you to attend a 1-3 hour session on how to address leaders to improve your community, at the [Location]". The invite was again intended to be unambiguously political (addressing leaders) but not domain specific. We included Busara's name at the suggestion of Ugandan staff who argued that in its absence the message would lack credibility and for related ethical considerations.
} 
venue as the lab session, attendance was voluntary and while the cost of transport was reimbursed, no additional incentive was provided for attending. ${ }^{9}$ Participation in this session involved participants engaging in a meeting, led by AFIEGO, our CSO partner, on a local development initiative that was geared towards improving their local community. In Kabale, the meeting discussed issues of off-grid energy and climate, while in Kampala it discussed healthcare. In both locations, invitation procedures were the same and Busara Center staff were responsible for recording attendance and identifying details to match to lab data. Their attendance at this meeting was the primary political activity outcome measure.

\subsection{Data collection procedure}

The laboratory session ${ }^{10}$ comprised a number of tasks and audio recordings, which were programmed in zTree, and which participants engaged through tablets mounted on desks. All text was translated and back-translated into Luganda for Kampala and Rukiga for Kabale.

First, participants were randomized into listening to one of four treatment audio messages. Randomization occurred at the individual level and was embedded within the experimental zTree file. Each treatment audio lasted about 5 minutes and was played through headphones. As such, participants could not hear audios of other participants in the session, ensuring the integrity of treatment assignment.

Participants then performed a short effort task called the 'grid task', which was incorporated into the design as a form of distraction, and in order to make the political themes from the treatment audios less salient.

Next, participants were invited to 'take a short break', and listened to the attention activity audio-reel. Immediately after this, participants answered the set of 15 questions that constituted the attention measures. Participants then completed the 10-item self-efficacy questionnaire. Payout was then calculated at the end of the session. ${ }^{11}$

\footnotetext{
${ }^{9}$ CSOs typically provide transport reimbursement for attendance at meetings of this kind as a matter of course. The reimbursed amount was unlikely to represent an excessive or desirable payment in itself, for these participants.

${ }^{10}$ Upon arrival to the mobile lab facility, we registered participants, obtained written consent, gave a briefing on the session and rules, and collected additional demographic information.

${ }^{11}$ Compensation of 7000 Ugandan Shillings (UGX) was provided for attendance (roughly 1.9 USD), an additional UGX 7000 was provided for transport, and 1750 UGX was provided as a bonus for punctuality
} 
After they collected their final payout, respondents were asked if they would be willing to participate in a community meeting on how to best address their leaders, where they were told that they would be able to express their opinions and participate in activities. Several days later, participants were sent text messages to actually attend the community meeting. Busara staff registered all attendees at the door using contact numbers - participants were asked to display their invite message.

\subsection{Empirical Strategy}

We use the following model to estimate the treatment effect for each of our outcome variables, where $i$ denotes the participant.

$$
y_{i}=\beta_{0}+\beta_{1} T_{R, i}+\beta_{2} T_{P, i}+\beta_{3} T_{D, i}+\varepsilon_{i}
$$

Here, $y_{i}$ is the outcome of interest measured at the level of the individual respondent i. $T_{R, i}$ is an indicator taking a value of 1 if individual $i$ was assigned to the rights information condition, and 0 otherwise. $T_{P, i}$ is an indicator taking a value of 1 if individual $i$ was assigned to focus on past success condition, and 0 otherwise. $T_{D, i}$ is an indicator taking a value of 1 if individual $\mathrm{i}$ was assigned to demonstration of civic engagement condition, and 0 otherwise. The omitted category is participants assigned to the control condition. $\varepsilon_{i}$ is an individual error term. This model is estimated with and without a vector of control variables, which includes the following: (i) location, (ii) age, (iii) gender, and (iv) education level, (v) session date ${ }^{12}$. Given random assignment to treatment conditions, the $\beta j$ variables identify the treatment effects of each of our interventions.

This model is estimated using OLS. Finally, for the binary outcomes (both attendance at the meeting and willingness to attend) we conduct logistic regressions as an additional robustness check.

(roughly 0.5 USD). Participants also received incentives for completing the 'Grid task' and for correct answers in the attention questionnaire.

12 Age is missing for 135 participants, dropping the sample down to 673 when we run the regression including the control vector. This is balanced across treatment groups. 
Given that each test represents a test of treatment effects for an independent theoretical construct, we do not apply multiple hypothesis testing corrections. In order to limit the rate of false positives, we focus analysis on primary outcomes for each construct.

The results section proceeds as follows. First, we show the results for the analysis of our primary outcomes. Next, we present results for our secondary outcomes followed by results of the manipulation check to observe if the treatments had any effect on self-efficacy. Finally, we briefly review the analysis of heterogeneous effects and provide a short discussion from the exploratory qualitative exercise.

\section{Results}

For all primary and secondary outcomes for civic engagement, none of the interventions generate significant positive effects across models. Only for pre-political attention, a secondary outcome, do we observe significant effects at the $5 \%$ level in the model with control variables, though these are relatively small in magnitude. Finally, the only consistently significant result across our primary outcomes and across models is that the story demonstrating political engagement decreases both political activity (attendance at a community meeting) and political attention.

\subsection{Primary Outcomes}

\subsubsection{Attendance at a community meeting}

Across all groups, rates of attendance were near $30 \%$ of participants. The rights intervention and story demonstrating engagement yielded lower proportions of participants attending the meeting, compared to the control group (See Figure 2 and Table 3). The difference was significant at the $10 \%$ level for rights information $(\mathrm{t}=-1.79 ; \mathrm{p}=0.074)$ and demonstration of engagement $(\mathrm{t}=-1.86 ; \mathrm{p}=0.064)$, and significant at the $5 \%$ level for demonstration of engagement when control variables are added to the model $(\mathrm{t}=-2.42, \mathrm{p}=0.016)$. This represents a relatively practically significant result as it indicates an approximate 8-10 percentage point decrease in meeting attendance (24.5\% relative to the control group) due to listening to the story of demonstrated engagement. 


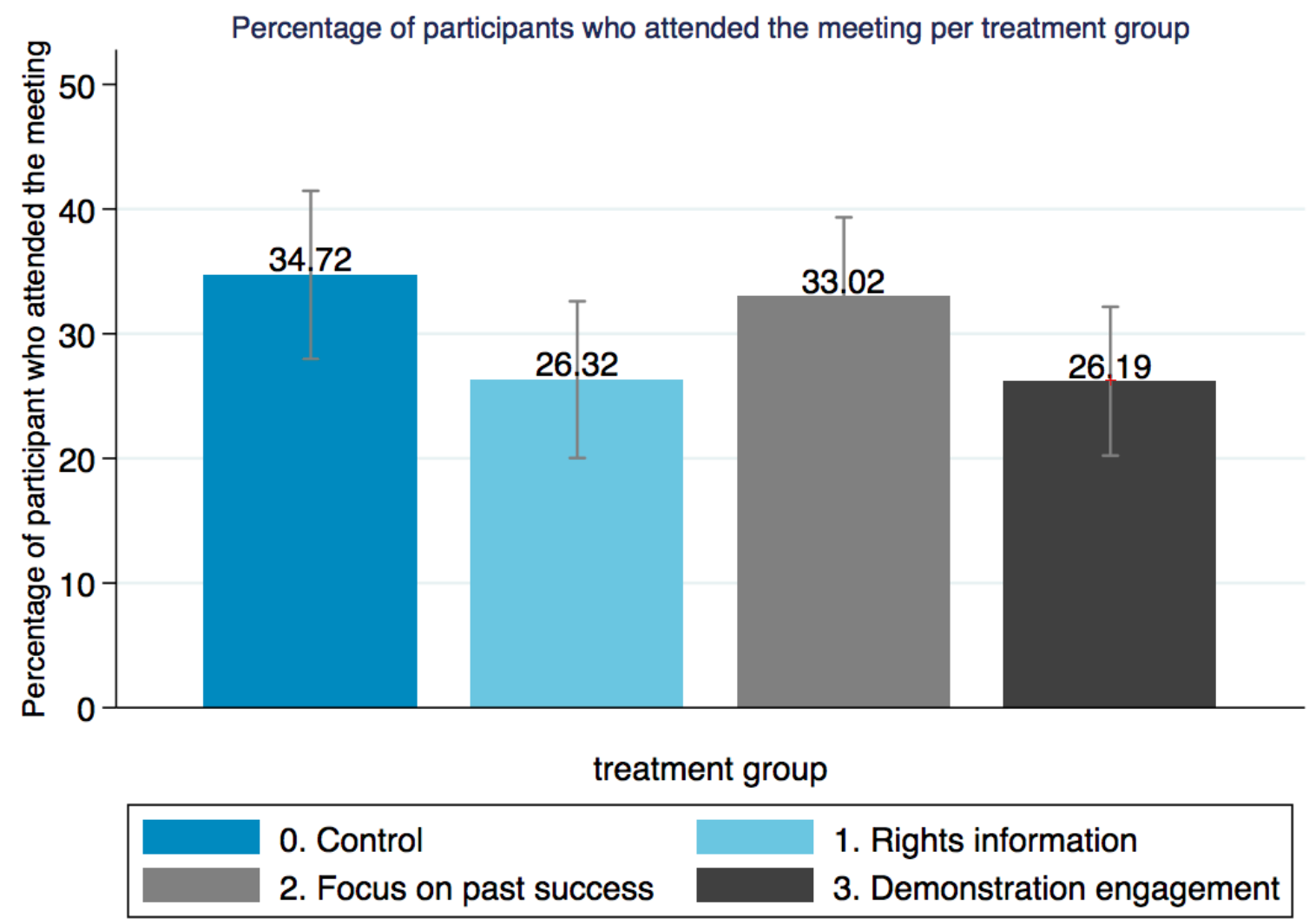

Figure 2. Treatment effects on meeting attendance

Table 3. Regression Results for Primary Outcomes

\begin{tabular}{cccc}
\multicolumn{2}{c}{ Attended the } & Meeting & \multicolumn{2}{c}{ Political Attention } \\
\hline Basic & With & Basic & With \\
Model & Controls & Model & Controls \\
\hline
\end{tabular}

\section{Treatments}

Rights information

$-0.084 *$

$-0.101^{*}$

$-0.168$

$-0.188$

Focus on past success

$(0.047)$

$(0.052)$

$(0.127)$

$(0.131)$

$-0.017$

$-0.016$

$-0.262 * *$

$-0.181$

$(0.047)$

(0.054)

$(0.122)$

$(0.124)$

Demonstration of engagement

$$
-0.085^{*}
$$

$-0.124 * *$

$-0.289 * *$

$-0.288^{* *}$

(0.046)

(0.051)

(0.127)

(0.126)

\section{Control variables}

Primary School

$$
\begin{gathered}
-0.072 \\
(0.087)
\end{gathered}
$$$$
0.320
$$

Secondary School 


\begin{tabular}{|c|c|c|c|c|}
\hline & & $(0.088)$ & & $(0.203)$ \\
\hline \multirow[t]{2}{*}{ Some tertiary } & & -0.032 & & $0.613^{* *}$ \\
\hline & & $(0.102)$ & & $(0.249)$ \\
\hline \multirow[t]{2}{*}{ Advanced Tertiary } & & -0.100 & & $1.401 * * *$ \\
\hline & & $(0.098)$ & & $(0.225)$ \\
\hline \multirow[t]{2}{*}{ Age } & & 0.001 & & -0.003 \\
\hline & & $(0.002)$ & & $(0.004)$ \\
\hline \multirow[t]{2}{*}{ Gender } & & -0.014 & & $-0.520 * * *$ \\
\hline & & $(0.039)$ & & $(0.099)$ \\
\hline \multirow[t]{2}{*}{ Location } & & -0.024 & & -0.134 \\
\hline & & $(0.038)$ & & $(0.095)$ \\
\hline \multirow[t]{2}{*}{ Session Order } & & 0.006 & & -0.017 \\
\hline & & $(0.004)$ & & $(0.011)$ \\
\hline \multirow[t]{2}{*}{ Constant } & $0.347 * * *$ & $0.373 * * *$ & $2.573 * * *$ & $2.557 * * *$ \\
\hline & $(0.034)$ & $(0.129)$ & $(0.088)$ & $(0.304)$ \\
\hline Observations & 808 & 672 & 802 & 667 \\
\hline
\end{tabular}

Robust standard errors in parentheses. ${ }^{* * *} \mathrm{p}<0.01,{ }^{* *} \mathrm{p}<0.05,{ }^{*} \mathrm{p}<0.1$

\subsubsection{Political attention outcome}

We measured political attention by testing recall of political information in the attention questionnaire administered after the information clips.

Most participants were able to provide the correct answer for roughly half of the political information questions (out of a total of 5), which is significantly greater than chance $(25 \%)$. We observed a significantly lower number of correct responses for the demonstration of engagement intervention compared to the control group $(t=-2.28 ; p=0.023)$, while the focus on past success intervention was significantly lower in the model without controls only (see Figure $3)$. 


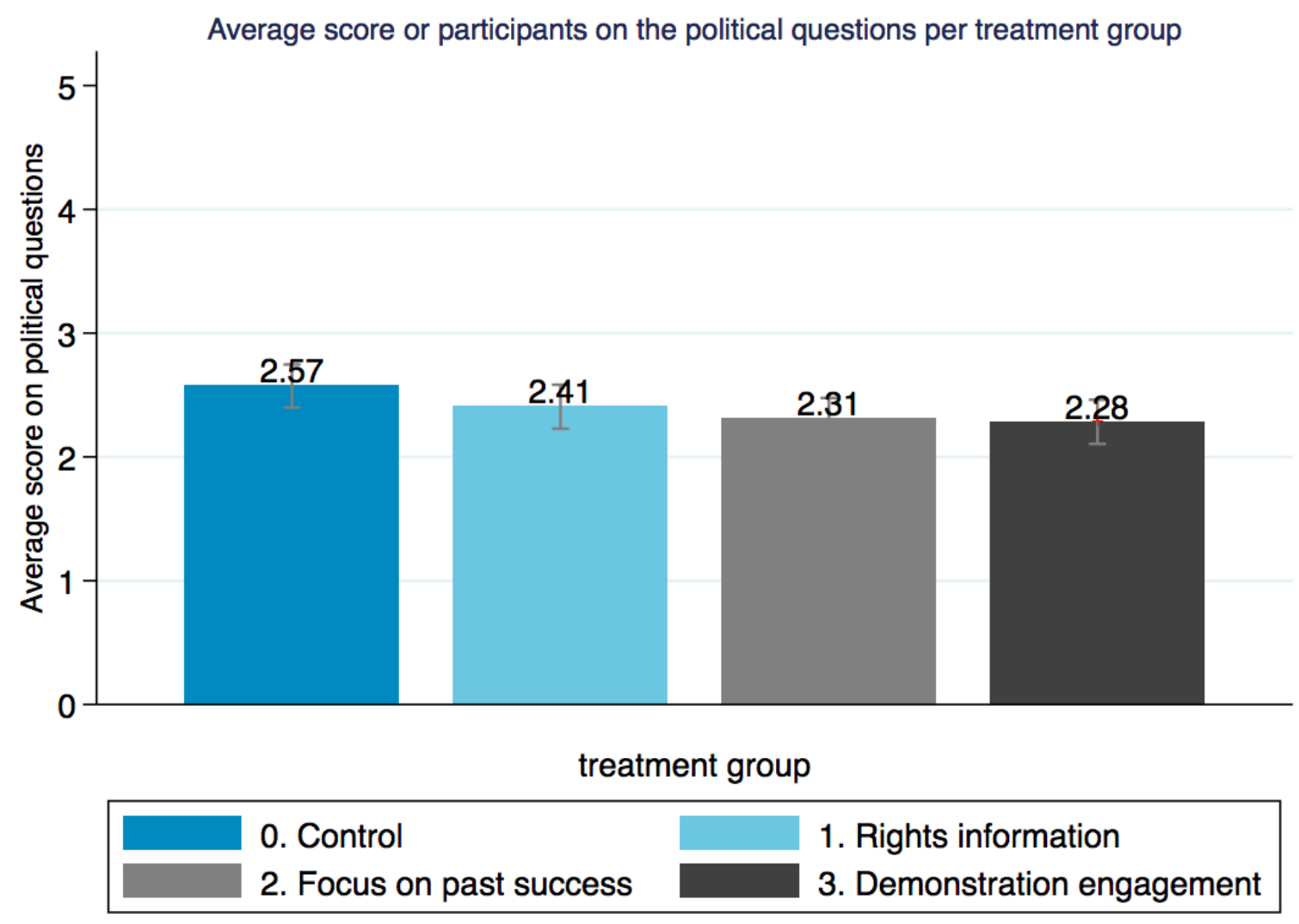

Figure 3. Treatment effects on political attention

\subsection{Secondary Outcomes}

\subsubsection{Willingness to attend a community meeting}

Overall, willingness to attend the community meetings was high across groups (roughly 91 percent were willing to attend; see Figure 4 and Table 4). There were no significant differences in willingness to attend between treatment conditions and control. However, what is notable is that actual attendance is far lower than this (roughly $30 \%$ of all participants), and as such approximately only 1 in 3 participants convert their intention to actual political activity. This suggests that measures focusing on self-reported intentions may be limited in their ability to indicate actual behaviors. 


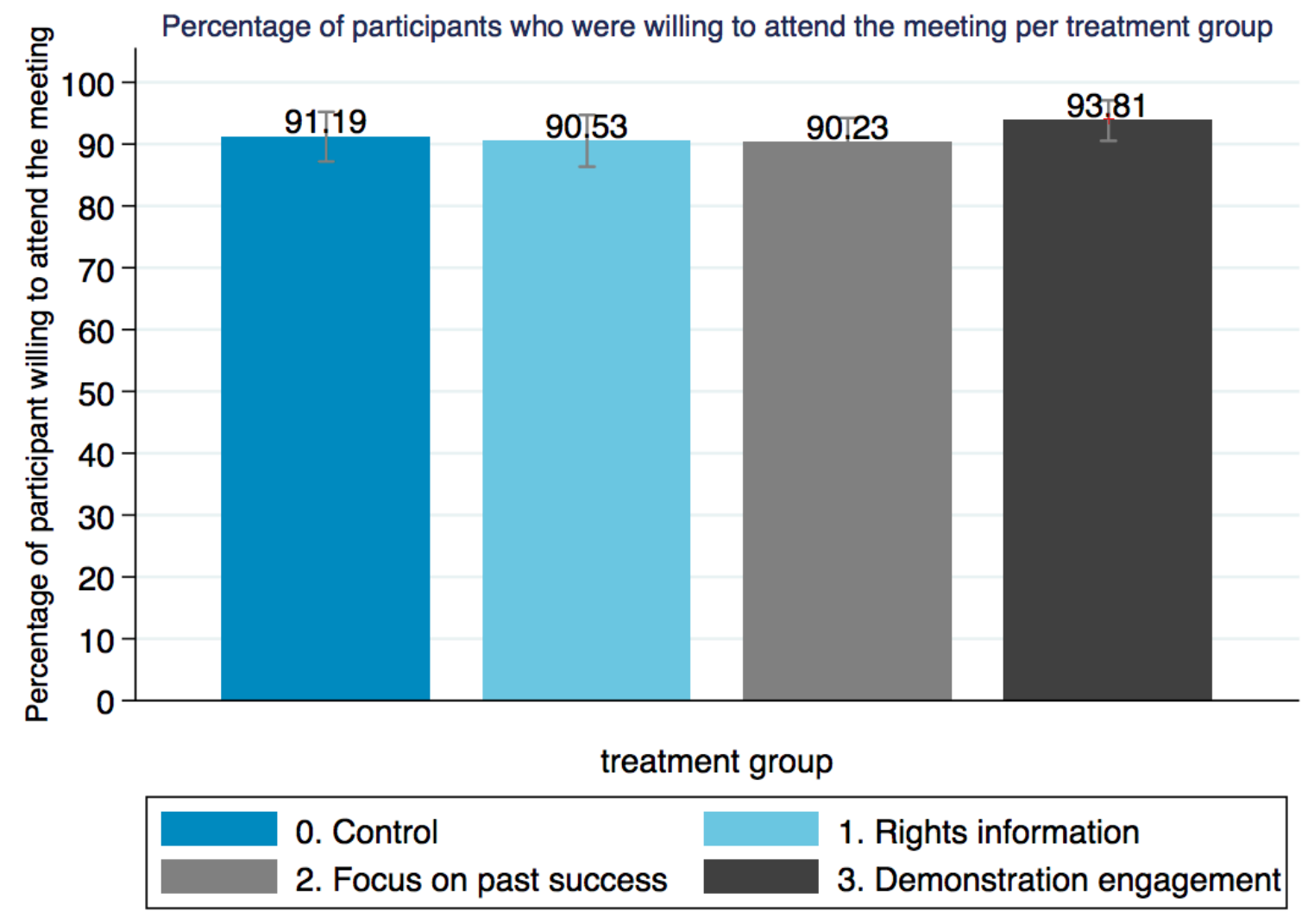

Figure 4 . Willingness to attend meeting by treatment

Table 4. Regression Results for Secondary Outcomes

\begin{tabular}{lcccc} 
& \multicolumn{2}{c}{$\begin{array}{c}\text { Willingness to attend } \\
\text { meeting }\end{array}$} & \multicolumn{2}{c}{ Pre-political Attention } \\
\cline { 2 - 5 } & $\begin{array}{c}\text { Basic } \\
\text { Model }\end{array}$ & $\begin{array}{c}\text { With } \\
\text { Controls }\end{array}$ & $\begin{array}{c}\text { Basic } \\
\text { Model }\end{array}$ & $\begin{array}{c}\text { With } \\
\text { Controls }\end{array}$ \\
\hline \multirow{2}{*}{$\begin{array}{l}\text { Treatments } \\
\text { Rights information }\end{array}$} & & & & \\
Focus on past success & -0.007 & -0.004 & $0.229^{*}$ & $0.266^{* *}$ \\
& $(0.030)$ & $(0.032)$ & $(0.129)$ & $(0.125)$ \\
Demonstration of engagement & -0.010 & -0.010 & 0.203 & $0.281^{* *}$ \\
& $(0.029)$ & $(0.031)$ & $(0.130)$ & $(0.130)$ \\
& 0.026 & 0.027 & -0.096 & -0.134 \\
& $(0.026)$ & $(0.028)$ & $(0.125)$ & $(0.120)$
\end{tabular}

Control variables

Primary School 
Some tertiary

Gender

Location

Constant

\begin{tabular}{lllll}
\hline Observations & 808 & 672 & 802 & 667 \\
\hline Robust standard & & & \\
\hline
\end{tabular}

Robust standard errors in parentheses $* * * \mathrm{p}<0.01, * * \mathrm{p}<0.05, * \mathrm{p}<0.1$

\subsubsection{Pre-political attention}

Participants in the rights information condition and 'focus on past success' condition obtained a significantly higher score on the pre-political attention measure, as compared to the control group, but this was only significant at the $5 \%$ level in the model including controls $(t=2.14$; $p=0.033$ and $t=2.17 ; p=0.030$ respectively; see Figure 5). Both the practically low significance of these differences (Between $8 \%$ and $10 \%$ of the control group mean ${ }^{13}$ ), and the only marginal statistical significance, suggest that each intervention was not successful at generating substantive change to pre-political attention. Pairwise comparisons and Wald Tests ${ }^{14}$ show that the demonstration of engagement treatment performed significantly worse than both rights information and focus on past success, but again this is substantively small and does not serve as a primary hypothesis test in this paper.

\footnotetext{
${ }^{13}$ Table A3 in the Appendix showing Minimum Detectable Effect Sizes (MDEs) for each outcome show that this study was powered to identify most practically meaningful effects

${ }^{14}$ See Appendix 6 for tables showing all pairwise comparisons for all outcome variables. Note, however, that we do not treat these as primary comparisons for testing hypotheses in this paper, given the intention to primarily compare the effect of each treatment to a control condition as a benchmark, and the consequent multiple hypothesis testing problem from introducing pairwise tests.
} 


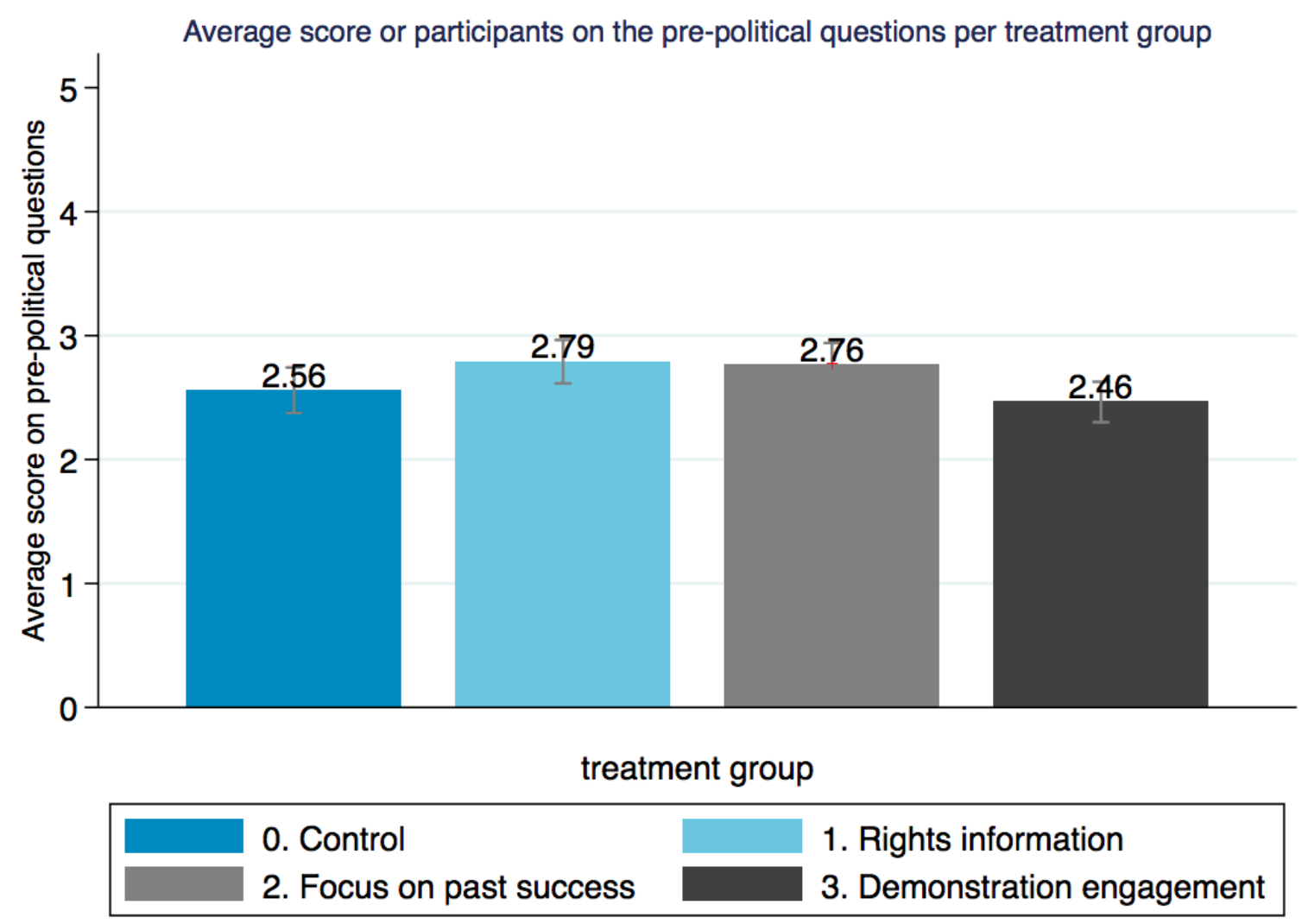

Figure 5. Pre-political attention by treatment

\subsection{Self-efficacy}

We observe no significant difference in self-efficacy scores on the Jerusalem and Schwarzer (1995) scale between the different groups. The scores for self-efficacy are between $86.3 \%$ and $88 \%$ for all groups, which reveals an overall high level of self-reported generalized selfefficacy (see Figure 6). Given that this was the hypothesized mechanism through which the interventions were expected to drive the effect on civic engagement, this failure to manipulate the mechanism could explain the lack of positive effects on civic engagement measures. 


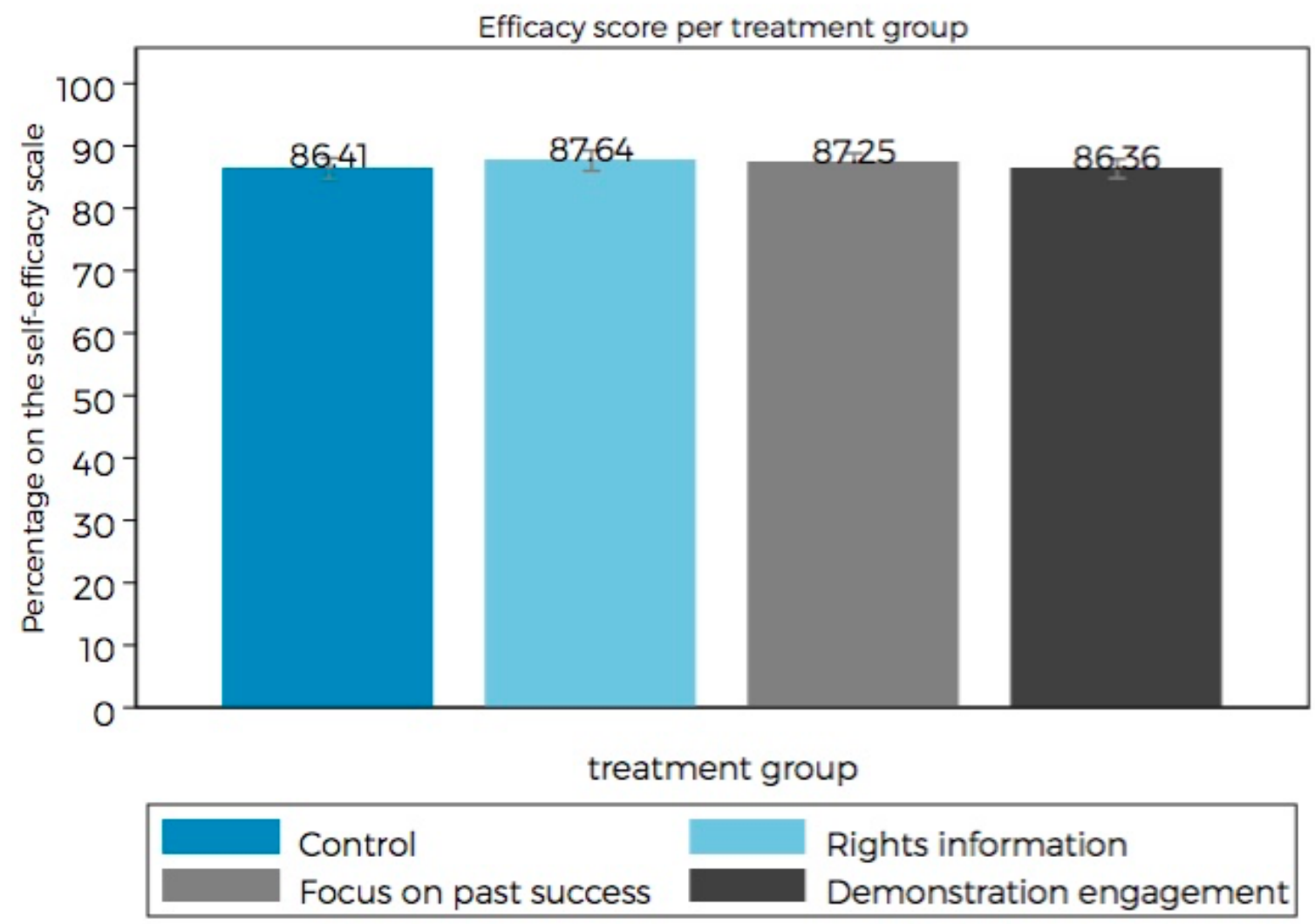

Figure 6. Generalized self-efficacy score by treatment

\subsection{Heterogeneous Effects}

Heterogeneous effects were analysed across age, location (Kabale vs Kampala), gender and session order. There were no significant heterogeneous treatment effects across the various sub-groups for any treatment, though general descriptive differences between groups are interesting for sub-group means of some outcomes (Appendix 7). ${ }^{15}$

\subsection{Exploratory Qualitative Results}

We undertook 25 qualitative phone interviews with participants assigned to the "Demonstration of engagement" treatment to gather more information about post-session behavior and reasons why they did attend or did not attend the community meeting. This

\footnotetext{
${ }^{15}$ Older participants performed worse on the pre-political attention measures. Participants in Kabale had lower scores of self-efficacy and lower scores on the pre-political attention measures than people in Kampala. More educated people had a higher score of self-efficacy, as well as a higher score on both the pre-political attention measure and on the political attention measure.
} 
intervention showed the highest score in a forecasting exercise on what people thought would be the most effective intervention at increasing civic engagement, and has a strongly plausible theory of change - similar interventions have induced behavior change in other fields (Lindemans, 2019; Dercon, Orkin \& Tafesse, 2014) - and yet had a significant negative effect on attendance at a community meeting. One explanation, which was a theme in the qualitative call data, is that individuals may have substituted other behaviors for the attendance at the meeting. For example, calling into radio (as Mama Dorah actually does in the story - see the full script in the appendix): two respondents indicated they had subsequently raised community issues by calling into local radio stations because they were 'inspired by Mama Dorah'. One quote reads: "I got a number of someone from KCCA [local radio station] and reported the issue. Now they punish those that throw rubbish in the trenches. It has helped us." Other anecdotal changes to behavior were mentioned by respondents, including one who had purchased a TV at work to follow news, something he attributed directly to hearing the story. This does not provide quantitative evidence of any effect, nor does it mitigate the possibility that other interventions also induced alternative unmeasured engagement behaviors, but sheds light on ways which real observable effects could have failed to appear in our single indicator of political activity. This suggests possible downward bias in treatment effects.

\section{Discussion}

\subsection{Limitations}

Firstly, in Kampala, approximately half the participants were not recruited from an existing subject pool, and were recruited through a snowballing technique. Participants recruited in this manner may have been told about the tasks and exercises the study contained in advance. Given randomization occurred on the individual level, this shouldn't impose a bias between treatment groups but could affect the measurement of certain outcomes and thus increase measurement error. In order to counteract this, we include a variable for session order, to control for differences between earlier and later sessions. This variable was not significant in any model.

Secondly, attention could be substitutable across different pieces of information in the attention task, and thus affect measures of both political and pre-political attention. Given that we expect treatments to positively affect attention to civic information, increased attention to political 
information could come at the expense of attention to pre-political information, or the reverse. The negative coefficient for the focus on past success intervention on political attention, but positive coefficient on pre-political attention highlights this possibility. The positive correlation (Cohen's $\mathrm{R}$ of 0.2897 ) between pre-political and political attention does not rule this possibility out, as attentive people would be more attentive to both, even if some attention was substituted from one to the other. Future studies should take care when using similar measures to focus outcomes on one construct of interest.

Thirdly, though the final outcome for political activity was the most recognizable form of nonelectoral participation identified from previous qualitative work, and the session was designed and run by a real CSO on general community involvement, this outcome could have been too narrow to capture all positive treatment effects on political engagement. There remain a number of ways in which individuals engage politically outside of this type of involvement, such as calling into radios, organizing petitions, talking about politics with friends, and directly addressing local leaders (Busara, 2017). This therefore generates the possibility of measurement error and bias in this outcome, as different engagement behaviors could be substitutable, limiting our capacity to identify treatment effects on political activity. That approximately $30 \%$ of the sample attended the meeting, however, is encouraging and suggests a significant endorsement of this meeting as an engagement construct. Given existing evidence, however, we can only conclude that the interventions did not increase political activity in the form of attending a community meeting.

Finally, following from the above point, the 'Demonstration of engagement' treatment may have specifically contributed to a substitution towards 'calling into radio' rather than attending a meeting. All treatments were crafted to be as similar as possible across different factors other than the specific self-efficacy-enhancing techniques, and to generically encourage 'addressing leaders' (in line with general notions of civic engagement and our specific outcomes). However, the 'Demonstration of engagement' treatment explicitly told a story about a woman who called into a radio station and thereby induced positive change in her community. Though this story predominantly focused on addressing leaders and included a component about a community meeting, it may have specifically induced calling into radio or similar behaviors, which we did not measure. As discussed above, this could bias the treatment effect for this intervention. No other treatments make meaningful reference to alternative behaviors. 


\subsection{Conclusion}

Civic engagement is important for the production of healthy polities and civil-society-state relations - this relationship is supported in Africa and in other regions where formal democratic institutions are less consolidated (Booth \& Cammack, 2013; Mansuri \& Rao, 2013). Civic engagement can thus support development and there is evidence showing that it can be induced. Yet, many recent experimental studies show limited evidence for what works to increase civic engagement in weak democracies and give few clues to activists on how to encourage engagement in such places (Soboleva, 2019; Raffler et al, 2018). Many interventions fail, and some that succeed require large-scale institutional support.

Behavioral science has shown that low-cost interventions can usefully induce behavior change, while self-efficacy has proven to be a strong correlate of political engagement and to causally produce useful political behaviours under certain conditions. We therefore design a set of lowcost tractable interventions to encourage self-efficacy and civic engagement. We use a laboratory experiment to examine how these different behaviorally informed communication interventions influence civic engagement as defined by civic attention and civic activity. Additionally, this experiment includes a number of features that may be useful for researchers designing similar experiments. We offer a new, more precise definition of civic engagement, demonstrate that a measure of civic activity intentions is a poor predictor of actual civic activity, and offer a new structured approach to treatment selection that combines a taxonomy of behavioral change techniques with a forecasting exercise.

None of our treatments increase civic engagement. Listening to the rights intervention and to a story demonstrating engagement discourage attendance to a community meeting. Listening to a story demonstrating engagement leads to the worst scores on the political attention measure out of all groups. Listening to the 'focus on past success' intervention and to the rights intervention increases scores on the pre-political attention task. Self-efficacy does not change with any intervention. Short self-efficacy encouraging audios thus appear largely ineffective at increasing both self-efficacy and civic engagement in this context, albeit with some effect on civic attention. The negative results on political attention and political activity from exposure to the demonstration of engagement story are specifically surprising; they are both counter to the hypothesized mechanism and contradict the results of the forecasting exercise, where 44 Kenyan and Ugandan intervention designers and field staff predicted it would be the most 
effective treatment. An exploratory qualitative follow-up with participants in this treatment group shows that a number of participants were 'inspired' by this story, and that several performed other civic engagement behaviors, such as calling into radio stations. This suggests that attending the meeting may have been substituted for alternative engagement behaviors. However, there is no systematic quantitative data supporting this ${ }^{16}$ and we do not draw any conclusion that this treatment had a positive effect on civic engagement.

These results are supported by those of a similar experiment conducted around the same time in Ukraine. Soboleva (2019) finds that self-efficacy-inducing interventions do not increase civic engagement intentions and behaviors, and for certain subgroups actually reduce them "increasing individuals' sense of efficacy without an accompanying change in the quality of democratic institutions leads to further political frustration”. This result underscores our finding and suggests that in the absence of avenues to usefully engage, psychological interventions could be ineffective or even backfire.

We conclude, first of all, that overcoming structural barriers to civic engagement is difficult (Herringshaw, 2017). Civic engagement may require collective action (Ostrom, 2000), positive feedback (Campbell, 2013; Chowdhury et al, 2018), government response (Sjoberg et al, 2017; Joshi \& McCluskey, 2018) and generally a means to overcome power imbalances (Rowlands, 2016). Psychological nudges are powerful; they have succeeded in a range of domains (Kahneman, 2011), and our experiment suggests that they can help encourage people to pay attention - in line with previous studies about similar treatments encouraging informationseeking behavior (Horn \& Keyman, 2016). Given the harder test of inducing a real act of political participation, these treatments did not succeed.

We additionally conclude that activists may be overusing rights language. A treatment that closely modelled existing CSO practice performed no better than a recording describing a table. Activists in Uganda and in similar situations may wish to consider other ways to communicate, which may be more familiar to their audiences (Mutua, 2009). Arves \& Braun (2019) have documented in a US context the ways in which different rights messages can backfire with certain audiences.

${ }^{16}$ We did not collect detailed follow-up data with participants in other treatment groups, nor systematic data for this group. 
We finally conclude with some insights for future research. Future experiments intending to manipulate self-efficacy should consider more comprehensive programs such as those used in McKelway (2019), albeit at a higher cost. Studies exploring the link between self-efficacyinducing interventions and civic engagement should also do so in conditions where opportunities to meaningfully engage exist. This supports a growing literature on the limitations of behavioral interventions to induce 'hard behaviors' in the context of large structural barriers to action (Soboleva, 2019; Raffler et al, 2018). For now, there remains no clear evidence of 'quick win' tractable behavioral interventions to increase civic engagement in weak democracies.

\section{Acknowledgments}

We are indebted to all our participants. We are grateful to the full team of data collectors who supported this work: Byakagaha Moses, Julius Mwesigwa, Kicoconco Judith, Muhwezi Derrick, Natukunda Bosco, Steven Sebulime, Nantale Rebecca, Judith Businge, Geofrey Mutole, and George Otuna. We thank AFIEGO, our CSO partner, and especially Diana Nabiruma, and salute all those organisations in Uganda and elsewhere who do the hard, slow embedded work of furthering civic engagement and prompting responsive governments. We are grateful to Gwyneth McClendon and Chaning Jang for their thoughtful and generous comments on this paper, and to Ariana Keyman for her essential input throughout this project. We additionally wish to thank our employer, the Busara Center for Behavioral Economics, for giving us time to work on this. We thank Hrag Vosgerichian, who assisted with data analysis. Funding was provided by an anonymous donor.

\section{Contributions}

This was a team effort. TW conceived the research questions and experiment, developed definitions, led preceding qualitative work, and developed the treatments. NO developed the outcome measures, with assistance from DW. NO and JK programmed the experiment in zTree. NO and MM navigated research permissions. LW oversaw data collection, supported by PW. CO and MM managed the data collector team and led lab sessions. AE conducted data analysis and led follow-up qualitative work. TW, NO and AE jointly drafted this paper. 


\section{Literature Cited}

Adler, R. P., \& Goggin, J. (2005). What do we mean by "civic engagement"? Journal of Transformative Education, 3(3), 236-253.

AfroBarometer. (2018). Ugandans see shrinking freedom for political opposition,

Afrobarometer survey shows. Retrieved from http://afrobarometer.org/press/ugandans-see$\underline{\text { shrinking-freedom-political-opposition-afrobarometer-survey-shows }}$

Amna, E., \& Ekman, J. (2014). Standby citizens: diverse faces of political passivity. European Political Science Review, 6(2), 261-281.

Anderson, M. R. (2010), “Community psychology, political efficacy, and trust”, Political Psychology 31(1), 59-84.

Arves, S., \& Braun, J. (2019). On Solid Ground: Evaluating the Effects of Foundational Arguments on Human Rights Attitudes. Human Rights Review, 1-24.

https://doi.org/10.1007/s12142-019-0545-7

Bandura, A. (1982). Self-efficacy mechanism in human agency. American Psychologist, $37(2), 122$.

Bandura, A., \& Schunk, D. H. (1981). Cultivating competence, self-efficacy, and intrinsic interest through proximal self-motivation. Journal of Personality and Social Psychology, 41(3), 586.

Banerjee, A. V., Banerji, R., Duflo, E., Glennerster, R., \& Khemani, S. (2008). Pitfalls of participatory programs: Evidence from a randomized evaluation in education in India. The World Bank.

Berger, B. (2009). Political theory, political science and the end of civic engagement. Perspectives on Politics, 7(2), 335-350.

Björkman, M., \& Svensson, J. (2009). Power to the people: evidence from a randomized field experiment on community-based monitoring in Uganda. The Quarterly Journal of Economics, 124(2), 735-769.

Blair, G., Littman, R., \& Paluck, E. L. (2017). Motivating the adoption of new communityminded behaviors: An empirical test in Nigeria.

Booth, D., \& Cammack, D. (2013). Governance for Development in Africa: Solving Collective Action Problems. London; New York: Zed Books. 
Boulding, C. E. (2010). NGOs and Political Participation in Weak Democracies:

Subnational Evidence on Protest and Voter Turnout from Bolivia. The Journal of Politics, 72(2), 456-468. https://doi.org/10.1017/S0022381609990922

Brady, H. E., Verba, S., \& Schlozman, K. L. (1995). Beyond Ses: A Resource Model of Political Participation. The American Political Science Review, 89(2), 271-294. https://doi.org/10.2307/2082425

Bratton, M. (2012). Citizen perceptions of local government responsiveness in Sub-Saharan Africa. World Development, 40(3), 516-527.

Buntaine, M. T., Daniels, B., \& Devlin, C. (2018). Can information outreach increase participation in community-driven development? A field experiment near Bwindi National Park, Uganda. World Development, 106, 407-421.

Busara Center for Behavioral Economics. (2017) Community Meetings in Uganda: Qualitative Review.

Campbell, D. E. (2013). Social networks and political participation. Annual Review of Political Science, 16, 33-48.

Caprara, G. V., Vecchione, M., Capanna, C. \& Mebane, M. (2009), “Perceived political selfe efficacy: Theory, assessment, and applications", European Journal of Social Psychology 39(6), 1002-1020.

Cheeseman, N., \& Klaas, B. (2018). How to Rig an Election. New Haven: Yale University Press.

Charness, G., Gneezy, U., \& Kuhn, M. A. (2013). Experimental methods: Extra-laboratory experiments-extending the reach of experimental economics. Journal of Economic Behavior \& Organization, 91, 93-100.

Chowdhury, A., Dunning, T., Grossman, G., Humphreys, M., Hyde, S. D., McIntosh, C., \& Nellis, G. (2018). 11 Meta-Analysis. In Metaketa I: Information, accountability, and cumulative learning. Cambridge University Press. Retrieved from https://egap.org/sites/default/files/pdfs/Metaketa\%20I Chs\%202\%20and $\% 2011$ for $\% 20 \mathrm{EG}$ AP\%20Vanderbilt.pdf

Dahl, R. A. (1963). Modern political analysis. Englewood Cliffs, N.J.: Prentice-Hall. Retrieved from https://www.worldcat.org/title/modern-political-analysis/oclc/255573 
Dahlstrom, M. F. (2014). Using narratives and storytelling to communicate science with nonexpert audiences. Proceedings of the National Academy of Sciences, 111(Supplement 4), 13614-13620.

Dercon, S., Orkin, K., \& Taffesse, A. (2014). The future in mind: Aspirations and forwardlooking behaviour in rural Ethiopia. London: Centre for Economic Policy Research.

DellaVigna, S., \& Pope, D. (2018). Predicting experimental results: who knows what? Journal of Political Economy, 126(6), 2410-2456.

Devas, N., \& Grant, U. (2003). Local government decision-making-citizen participation and local accountability: some evidence from Kenya and Uganda. Public Administration and Development, 23(4), 307-316. https://doi.org/10.1002/pad.281

Dunning, T., Grossman, G., Humphreys, M., Hyde, S. D., McIntosh, C., \& Nellis, G. (Eds.). (2018). Metaketa I: Information, accountability, and cumulative learning. Cambridge University Press. Retrieved from https://egap.org/sites/default/files/pdfs/Metaketa\%20I Chs\%202\%20and\%2011 for\%20EG AP\%20Vanderbilt.pdf

Ekman, J., \& Amnå, E. (2012). Political participation and civic engagement: Towards a new typology. Human Affairs, 22(3), 283-300. https://doi.org/10.2478/s13374-012-0024-1

Fioramonti, L. (2012), 'Micro-assistance to democracy: Two revolutions in promoting consolidation of democracy in developing countries', Strategic Review for Southern Africa $34(2), 110-127$.

Fischbacher, U. (2007). z-Tree: Zurich toolbox for ready-made economic experiments. Experimental Economics, 10(2), 171-178.

Fox, R. L., \& Lawless, J. L. (2011). Gendered perceptions and political candidacies: A central barrier to women's equality in electoral politics. American Journal of Political Science, 55(1), 59-73.

Gastil, J., \& Xenos, M. (2010). Of attitudes and engagement: Clarifying the reciprocal relationship between civic attitudes and political participation. Journal of Communication, 60(2), 318-343.

Gaventa, J., \& Barrett, G. (2012). Mapping the Outcomes of Citizen Engagement. World Development, 40(12), 2399-2410. https://doi.org/10.1016/j.worlddev.2012.05.014 
Gehlbach, S., Sonin, K., \& Svolik, M. W. (2016). Formal Models of Nondemocratic

Politics. Annual Review of Political Science, 19(1), 565-584.

https://doi.org/10.1146/annurev-polisci-042114-014927

Gerber, A. S., Green, D. P., \& Larimer, C. W. (2008). Social pressure and voter turnout:

Evidence from a large-scale field experiment. American Political Science Review, 102(1), $33-48$.

Gerring, J. (1999). What makes a concept good? A criterial framework for understanding concept formation in the social sciences. Polity, 31(3), 357-393.

Gist, M. E., \& Mitchell, T. R. (1992). Self-Efficacy: A Theoretical Analysis of Its Determinants and Malleability. Academy of Management Review, 17(2), 183-211. https://doi.org/10.5465/amr.1992.4279530

Golooba-Mutebi, F. (2004). Reassessing popular participation in Uganda. Public Administration and Development: The International Journal of Management Research and Practice, 24(4), 289-304.

Gottlieb, J. (2016), "Greater expectations: A field experiment to improve accountability in Mali”, American Journal of Political Science 60(1), $143\{157$.

Grossman, G., Humphreys, M., \& Sacramone-Lutz, G. (2014). "I wld like u WMP to extend electricity 2 our village": On Information Technology and Interest Articulation. American Political Science Review, 108(3), 688-705.

Grossman, G., Michelitch, K., \& Santamaria, M. (2017). Texting complaints to politicians: Name personalization and politicians' encouragement in citizen mobilization. Comparative Political Studies, 50(10), 1325-1357.

Grossman, G., Platas, M. R., \& Rodden, J. (2018). Crowdsourcing accountability: ICT for service delivery. World Development, 112, 74-87.

Haugerud, A. (1997). The culture of politics in modern Kenya (Vol. 84). Cambridge University Press.

Herringshaw, V. (2017). Addressing failure in ICT-enabled 'citizen voice - government responsiveness' interventions: unpacking core assumptions and essential components.

Retrieved from https://opendocs.ids.ac.uk/opendocs/handle/123456789/13442

Horn, S., \& Keyman, A. (2016). Self-Efficacy as a Driver of Civic Participation in Uganda. Unpublished manuscript, Nairobi, Kenya. 
Joshi, A., \& McCluskey, R. (2018). The art of 'bureaucraft': Why and how bureaucrats respond to citizen voice. Retrieved from https://opendocs.ids.ac.uk/opendocs/handle/123456789/13446

Kabunga, N. S., Mogues, T., Bizimungu, E., Erman, A., \& Van Campenhout, B. (2016). The State of Public Service Delivery in Uganda: Report of a Baseline Survey. Intl Food Policy Res Inst.

Kahneman, D. (2011). Thinking, fast and slow (Vol. 1). Farrar, Straus and Giroux New York.

Kalla, J. L., \& Broockman, D. E. (2018). The minimal persuasive effects of campaign contact in general elections: Evidence from 49 field experiments. American Political Science Review, 112(1), 148-166.

Khemani, S., Dal Bó, E., Ferraz, C., Finan, F. S., Stephenson Johnson, C. L., Odugbemi, A. M., ... Abrahams, S. D. (2016). Making politics work for development : harnessing transparency and citizen engagement (No. 106337) (pp. 1-281). The World Bank. Retrieved from http://documents.worldbank.org/curated/en/268021467831470443/Makingpolitics-work-for-development-harnessing-transparency-and-citizen-engagement Kibirige, F. (2018). Slowly Growing or Stunted? How Delivery of Electoral, Political and Economic Goods Impacts Support for Democracy in Uganda.

Mansuri, G., \& Rao, V. (2013). Can participation be induced? Some evidence from developing countries. Critical Review of International Social and Political Philosophy, 16(2), 284-304. https://doi.org/10.1080/13698230.2012.757918

Marks, R., Allegrante, J. P., \& Lorig, K. (2005). A review and synthesis of research evidence for self-efficacy-enhancing interventions for reducing chronic disability: Implications for health education practice (part I). Health Promotion Practice, 6(1), 37-43. https://doi.org/10.1177/1524839904266790

McClendon, G., \& Riedl, R. B. (2015). Religion as a stimulant of political participation: Experimental evidence from Nairobi, Kenya. The Journal of Politics, 77(4), 1045-1057. McEntire, K. J., Leiby, M., \& Krain, M. (2015). Human rights organizations as agents of change: An experimental examination of framing and micromobilization. American Political Science Review, 109(3), 407-426. 
McGee, R., Edwards, D., Anderson, C., Hudson, H., \& Feruglio, F. (2018). Appropriating technology for accountability: messages from Making All Voices Count (p. 30). Making All Voices Count; Institute for Development Studies. Retrieved from https://www.makingallvoicescount.org/publication/appropriating-technologyaccountability-messages-making-voices-count-2/

McKelway, M. (2019) Vicious and Virtuous Cycles: Self-Efficacy and Employment of Women in India. Unpublished manuscript.

Michie, S., Richardson, M., Johnston, M., Abraham, C., Francis, J., Hardeman, W., ... Wood, C. E. (2013). The behavior change technique taxonomy (v1) of 93 hierarchically clustered techniques: building an international consensus for the reporting of behavior change interventions. Annals of Behavioral Medicine, 46(1), 81-95.

Michie, S., Van Stralen, M. M., \& West, R. (2011). The behaviour change wheel: a new method for characterising and designing behaviour change interventions. Implementation Science, 6(1), 42 .

Morrell, M. E. (2005). Deliberation, democratic decision-making and internal political efficacy. Political Behavior, 27(1), 49-69.

Mutua, M. (2018). Is the age of human rights over? In S. A. McClennen (Ed.), The Routledge Companion to Literature and Human Rights. Routledge. Retrieved from https://books.google.co.ke/books?hl=en\&lr=\&id=eQstCgAAQBAJ\&oi=fnd\&pg=PA450\&d $\mathrm{q}=$ Mutua, $+2009+$ rights\&ots=67vk917V14\&sig=ZIz4SUm174AdNj99G5A5Csaczx8\&redir $\underline{\text { esc }=y \# v=\text { onepage } \& \mathrm{q}=\text { Mutua } \% 2 \mathrm{C} \% 202009 \% 20 \text { rights } \& \mathrm{f}=\text { false }}$

Ostrom, E. (2000). Collective action and the evolution of social norms. Journal of Economic Perspectives, 14(3), 137-158.

Pandey, P., Goyal, S., \& Sundararaman, V. (2009). Community participation in public schools: impact of information campaigns in three Indian states. Education Economics, 17(3), 355-375. https://doi.org/10.1080/09645290903157484

Peixoto, T., \& Sifry, M. L. (2017). Civic tech in the global south. Washington, DC: World Bank and Personal Democracy Press.

Pettigrew, T. F., \& Tropp, L. R. (2011). Essays in social psychology. When groups meet: The dynamics of intergroup contact. New York, NY, US .... 
Preece, J. R. (2016). Mind the gender gap: An experiment on the influence of self-efficacy on political interest. Politics \& Gender, 12(1), 198-217.

Putnam, R. (1993). The prosperous community: social capital and public life. The American Prospect, 13(Spring), Vol. 4. Available online: http://www. prospect. org/print/vol/13 (accessed 7 April 2003).

Raffler, P., Posner, D. N., \& Parkerson, D. (2018). The weakness of bottom-up accountability: Experimental evidence from the Ugandan health sector. Unpublished Manuscript.

Reinikka, R., \& Svensson, J. (2005). Fighting corruption to improve schooling: Evidence from a newspaper campaign in Uganda. Journal of the European Economic Association, $3(2-3), 259-267$.

Robertson, I. H., Ward, T., Ridgeway, V., \& Nimmo-Smith, I. (1996). The structure of normal human attention: The Test of Everyday Attention. Journal of the International Neuropsychological Society, 2(6), 525-534.

Rowlands, J. (2016). Power in practice: Bringing Understandings and Analysis of power into Development Action in Oxfam.

Salami, S. O. (2010). Emotional intelligence, self-efficacy, psychological well-being and students attitudes: Implications for quality education. European Journal of Educational Studies, 2(3), 247-257.

Schwarzer, R., \& Jerusalem, M. (1995). Generalized self-efficacy scale. Measures in Health Psychology: A User's Portfolio. Causal and Control Beliefs, 1(1), 35-37.

Sjoberg, F. M., Mellon, J., \& Peixoto, T. (2017). The Effect of Bureaucratic Responsiveness on Citizen Participation. Public Administration Review, 77(3), 340-351. https://doi.org/10.1111/puar.12697

Soboleva, I. (2019). No Politics, Please! When Democracy Promotion Suppresses Political Engagement. Unpublished Manuscript (Available at https://www.dropbox.com/s/ky5un7b4pt9la94/Soboleva2019.pdf)

Solhaug, T. (2006). Knowledge and self-efficacy as predictors of political participation and civic attitudes: with relevance for educational practice. Policy Futures in Education, 4(3), $265-278$. 
Teorell, J. (2003). Linking Social Capital to Political Participation: Voluntary Associations and Networks of Recruitment in Sweden1. Scandinavian Political Studies, 26(1), 49-66. https://doi.org/10.1111/1467-9477.00079

Tripp, A. M. (2010). Museveni's Uganda: paradoxes of power in a hybrid regime (Vol. 6). Lynne Rienner Publishers Boulder, CO.

Twaweza. (2017). We the people: Ugandans' views on governance, information and citizen engagement (Policy Brief No. 2c). Dar es Salaam: Twaweza. Retrieved from https://www.twaweza.org/uploads/files/SzW-UG-Brief2c-Governance-FINAL.pdf Twaweza. (2018a). Clean and safe? Ugandans' experiences and opinions on affordable access to clean and safe water (Policy Brief No. 4). Dar es Salaam: Twaweza. Retrieved from https://www.twaweza.org/uploads/files/SzW Ug_r3_WASH\%20_Final.pdf

Twaweza. (2018b). The haves and the have nots: Ugandans' views and opinions on poverty, fairness and inequality (Policy Brief No. 3). Dar es Salaam: Twaweza. Retrieved from https://www.twaweza.org/uploads/files/SzW-UG-2018-Inequality-FINAL-web.pdf Valentino, N. A., Gregorowicz, K., \& Groenendyk, E. W. (2009). Efficacy, emotions and the habit of participation. Political Behavior, 31(3), 307.

Van Campenhout, B., Bizimungu, E., Smart, J., \& Kabunga, N. (2018). Impact pathways of a participatory local governance initiative in Uganda: a qualitative exploration. Development in Practice, 28(8), 1046-1056.

Vaughan, Everett M. Rogers, Arvind Singhal, Ramadhan M. Swalehe, P. (2000). Entertainment-education and HIV/AIDS prevention: A field experiment in Tanzania. Journal of health communication, 5(sup1), 81-100.

Young, L. E. (2019). The psychology of state repression: Fear and dissent decisions in Zimbabwe. American Political Science Review, 1-16.

Wood, R., \& Bandura, A. (1989). Impact of conceptions of ability on self-regulatory mechanisms and complex decision making. Journal of Personality and Social Psychology, 56(3), 407-415. https://doi.org/10.1037//0022-3514.56.3.407. 


\section{Appendices}

In these appendices, we provide the English language versions of the treatment audios and attention information questionnaire. Versions translated into Rukiga and Luganda are available on request. Additionally, we provide analysis of heterogeneity, MDEs, and the selfefficacy outcomes, and additional robustness check output.

\section{Appendix 1: Treatment audios}

\section{Text of control treatment}

We will talk about different things in this recording, but first I want to say that it is important that communities come together to communicate formally with their leaders.

The table is a basic piece of household furniture. It generally consists of a flat top that is supported by either a set of legs, pillars, or trestles. Most tables have four legs. However, some have three legs. Some Use a single heavy pedestal, or are attached to a wall. The tabletop may be made of stone, metal, wood, or a synthetic material such as a plastic. Table top surfaces can be designed in various shapes. These can be rectangular, square, rounded or oval.

The other defining characteristic of a table is its height, and this has risen with changes in seating. Some tables are low enough to serve low couches or to allow someone to sit on the floor, while more recent types are made higher to accommodate chairs.

Tables may be subdivided into categories based on whether the table is a fixed table or a mechanical table. A fixed table has a top that does not move in any way to expand or reduce in size. The tops on fixed tables can be quite sizable and may be supported by a single column. Mechanical tables have tops or legs that move, fold, drop, or in some way may be changed in order to save space or make them more flexible. Mechanical tables include those with legs that fold up or collapse if a mechanism is unlocked.

Tables are designed for very many different uses. Their uses are best identified based on the types of tables. For example: there are stands that are flat in the market, which are good for displaying goods. Then there is the dining table, is used for seated persons to eat meals in homes or in restaurants. Some people may own a bedside table is used to place an alarm clock and a lamp. There are desks, which are tables that we use for working in offices in some types 
of job. There are also a range of specialized types of tables, such as sewing tables used for sewing.

Tables should be strong and hard wearing, so that they will last a long time. It should also be good value for money. For some people, style is also an extremely important part of a table. They want a table that looks good.

The appearance of the table may vary as a result of many factors. These include changing stylistic preferences, the different materials that can be used for the table or methods for its construction, and new table forms that are the result of different needs. There are numerous table styles that exist. These include tables designed to stay compact. These are excellent space savers and make more space available in a room to move about. There are other styles that can be adjusted to make tables look bigger while others are designed to magically extend these tables on need basis. A variety of other tables have been furnished with chests of drawers and shelves, and in some cases with cupboards.

To put it simply, tables are pieces of furniture that have many different uses, and can be found in many different types of room.

We have talked about several different things. I want to finish by talking about the importance of playing a part in society. It is important for each person to play a part in society. Communities should come together. When they face problems, communities should come together to communicate formally with their leaders. In this way, people can request that their leaders solve the problems of the community. They can ask leaders to help make things better. The problems a community faces are more likely to be solved when they come together to communicate formally with their leaders.

Thank you for listening to this recording.

\section{Text of rights information treatment}

We will talk about different things in this recording, but first I want to say that it is important that communities come together to communicate formally with their leaders.

We each of us have the right to do certain things. Each and every human has certain rights. 
Having rights means you can choose to ask for certain things that are due to every human. These rights are a part of you, and cannot be taken away, for the whole of your life. That means that you have the capability to do certain things.

This is true all over the world, including Uganda. Under Ugandan law, men, women and children all have their equal rights .Under the Constitution of Uganda, it says that each person has the fundamental right to social justice and economic development. The Constitution therefore says that all developmental efforts should be directed at ensuring the maximum social and cultural well-being of the people. The Constitution also says that all Ugandans should enjoy access to education, health services, and clean and safe water. They also have the right to work, decent shelter, adequate clothing and food security. They even have the right to pension and retirement benefits. So long as people are patriotic and loyal to Uganda, and so long as they perform their duties and contribute to national development, each person holds these rights. Different levels of local and national government are tasked with ensuring that these rights are delivered to the people.

There are many different rights that people have. They have the right to life, and to freedom. They have the right not to be taken as a slave, and the right to not be tortured. It is against someone's rights to arbitrarily arrest someone. Each person has the right to a fair and equal hearing in a court of law. People have the right to marry, and the right to worship in line with their religion. Importantly people also have the right to own property, and this cannot be taken away by anyone without a fair process. So you see, people have many rights.

The recognition of these rights is the foundation of freedom, justice and peace in the world. Whenever we have failed to recognize them, and shown disregard and contempt for these rights, it has resulted in violence and terrible acts and fear among the people. That is why rights are so important, and why it is so important that people are aware of their rights.

Among those many different rights is the right to come together as a community and communicate formally with your leaders. Everyone has the right to do this. They have the right to contribute loyally to national development, by raising up their voices. Attending meetings is one way of doing this or calling in to a radio debate show. There are many ways in which people can engage with their leaders. This is especially true when there are problems in a community and not everyone's rights are being met - if people's rights are not being met then 
people have the ability to come together and request that leaders solve the problems. Doing this can help ensure that the rights of the people are respected. Rights therefore give you the ability to be part of a community that comes together to communicate formally with its leaders.

A common understanding of these rights and freedoms is extremely important, and they must be respected, because these rights are held by every person.

We have talked about several different things. I want to finish by talking about the importance of playing a part in society. It is important for each person to play a part in society. Communities should come together. When they face problems, communities should come together to communicate formally with their leaders. In this way, people can request that their leaders solve the problems of the community. They can ask leaders to help make things better. The problems a community faces are more likely to be solved when they come together to communicate formally with their leaders. Thank you for listening to this recording.

\section{Text of 'focus on past success' treatment}

We will talk about different things in this recording, but first I want to say that it is important that communities come together to communicate formally with their leaders. I am going to ask you to think about a specific time in your life that you felt capable of achieving things. Especially, I want you to think of a time when you succeeded in being able to say something important to someone who is a leader in your community or who has a lot of influence in your community. Can you recall a time when you felt that you could help solve a problem for your community, if you tried hard enough?

[Pause 7 seconds]

Do you have an example in your mind? It should be an example of a time when you succeeded in being able to say something important to someone who is a leader in your community.

[Pause 5 seconds] 
Really try hard to remember exactly how it felt.

What exactly did you do in that time? How exactly did you feel?

[Pause 7 seconds]

You might want to think about how you felt capable of achieving things. You might want to think about whether, if someone opposed you, you would have been able to find the means and ways to get what you want. You might want to think about whether it was easy for you to stick to your aims and accomplish your goals.

[Pause 5 seconds]

Recalling that example from your life, and how it felt, consider whether you were confident that you could deal efficiently with unexpected events. Perhaps you felt resourceful, and able to handle unforeseen situations. Perhaps you felt that you could solve most problems, if you invested the necessary effort.

Still thinking about the example from your life. What feelings does it inspire in you? Perhaps you think "I can remain calm when facing difficulties." Maybe you remember that you can rely on your coping abilities. Perhaps you know that when you are confronted with a problem, you can usually find several solutions. Even if you are in trouble, you may remember that you can usually think of a solution.

At the times in your life when you feel like that, perhaps it feels like you can handle whatever comes your way. You may know that you and the people around you think that you are a person who is able to do things like this. You may think that you will have no problems handling a challenging situation and in the end you will find it easy to be part of a community that comes together to communicate formally with its leaders.

When you feel like that, perhaps you feel capable. You may feel that you would be able to be part of a community that comes together to communicate formally with their leaders.

Especially when you have experienced success in the past, it can show that it is much easier than we think to achieve difficult things again. Perhaps you feel that you can contribute another to the many stories of people achieving great things when they are part of a 
community that comes together to communicate formally with its leaders.

Think one last time about your past success, and how it can show that you have the capability to achieve more in the future.

[Pause 3 seconds]

Believe in yourself, and in your ability to do this.

We have talked about several different things. I want to finish by talking about the importance of playing a part in society. It is important for each person to play a part in society. Communities should come together. When they face problems, communities should come together to communicate formally with their leaders. In this way, people can request that their leaders solve the problems of the community. They can ask leaders to help make things better. The problems a community faces are more likely to be solved when they come together to communicate formally with their leaders. Thank you for listening to this recording.

\section{Text of demonstration of engagement story treatment}

We will talk about different things in this recording, but first I want to say that it is important that communities come together to communicate formally with their leaders.

There are so many stories of people demonstrating that they can do this. We are going to tell you about one example of people coming together as a community to communicate formally with their leaders. It is only one example, and there are many other stories we could tell you. In this example, we can see how people proved they were capable of doing this.

The first story is a story that has been repeated all over Uganda. But this specific story is the story of an ordinary woman called Mama Dorah and her family, and the change she was able to make.

In Mama Dorah's community, the people were really suffering. The health workers were not showing up to work. The health center did not have enough of the right medicines. The roads 
were impassable, with so many potholes. Even the water was not clean or safe for people to drink. Perhaps you have seen some of these problems yourself. To start with, the people felt so helpless to solve these problems. They did not know what to do.

There was one particular person: a woman named Mama Dorah, doing housework at home with her children. She faced all of these problems; the health center was so bad, and the water was so bad, and her biggest fear was that her children may become ill. What if she could not get the proper treatment for them?

But then, there was a debate on the local radio station. The radio host invited people to call in, and communicate formally with their leaders. Mama Dorah heard this show, and said to her neighbor "I think I should call in." And she did. She had to try a few times, but eventually she got through and was put on the air.

She spoke so movingly about her fears for her children. Because her family were suffering, she raised up her voice. She wasn't the only one. So many people called in, and they described the problems they faced each day.

And their leaders were listening to this show. The LCIII called the head of the radio station, and asked him to organize a meeting. Some important leaders were there to listen. The LCI, LCII, LCIII, parish chief, councilors, CSOs and the media - they were there to hear the voices of more than 300 people. People proved that they could come together to communicate formally with their leaders. And so the roads were repaired, and the local government has promised to find money to improve the health center.

This just goes to show that people can come together as a community to communicate formally with their leaders. Even an ordinary person like Mama Dorah found that she was capable of doing this. It is not always easy to do this, but Mama Dorah found that it was much easier than she thought it was going to be. Perhaps you feel a bit like Mama Dorah at the start of this story, facing so many problems. But you are capable of imitating her. You can be part of a community that comes together to communicate formally with your leaders. There are so many stories from around Uganda and even from this area, that prove that people are capable of doing this, if they decide to. 
We have talked about several different things. I want to finish by talking about the importance of playing a part in society. It is important for each person to play a part in society. Communities should come together. When they face problems, communities should come together to communicate formally with their leaders. In this way, people can request that their leaders solve the problems of the community. They can ask leaders to help make things better. The problems a community faces are more likely to be solved when they come together to communicate formally with their leaders. Thank you for listening to this recording.

\section{Appendix 2: Civic Attention Questions}

Those questions all correspond to audio clips providing the right information.

\section{List of political questions}

1. With which government did Uganda reach an agreement to construct an oil pipeline from Hoima?

2. Out of the 7 by-elections held between May 2016 and January 2017, how many has the NRM won?

3. Which organization mentioned in the clip was founded in 1997 as a platform for CSOs to communicate?

4. To which country did CSO leaders and government officials travel to be trained to deliver social programs?

5. When was Uganda's Constitution officially adopted?

\section{List of pre-political questions}

1. What practice discussed in the clip is under heavy debate because it is seen as humiliating to women?

2. Which disease mentioned in the clip are Ugandans collecting funds to send people for specialized treatment abroad for?

3. What, according to the clip, did women in western Uganda provide to help improve farming practices and increase farm incomes?

4. What disease has Uganda reduced significantly in the last decade? 
5. What cause of death was greatly reduced from the establishment of community-run health clinics in one district?

\section{List of non-political questions}

1. What portion of Uganda's population is Christian?

2. The Uganda national football team drew to which team in the African Nations Championship?

3. Uganda has $11 \%$ of the World's species of which type of animal?

4. Approximately how many people live in Uganda?

5. What substance makes up roughly $60 \%$ of the human body's mass? 


\section{Appendix 3: Regression Results for Generalized Self-efficacy}

Table A1. Regression Results for Generalized Self-efficacy Outcome

\section{Generalized Self \\ Efficacy Index}

Basic With

Model Controls

\section{Treatments}

Rights information

$\begin{array}{cc}0.495 & 0.377 \\ (0.471) & (0.528) \\ 0.338 & 0.421 \\ (0.460) & (0.503) \\ -0.020 & -0.344 \\ (0.457) & (0.510)\end{array}$

\section{Control variables}

Primary School

Secondary School

Some tertiary

Advanced Tertiary

Age

0.004

Gender

(0.016)

0.122

(0.367)

Location

Session Order

Constant

$$
\begin{array}{cc}
34.563 * * * & 33.705 * * * \\
(0.331) & (1.512)
\end{array}
$$

\begin{tabular}{lll}
\hline Observations & 804 & 669 \\
\hline Robust standard errors in parentheses & \\
$* * * \mathrm{p}<0.01, * * \mathrm{p}<0.05, * \mathrm{p}<0.1$ &
\end{tabular}




\section{Appendix 4: Regression Results for Logit Estimation on Binary Outcomes}

Table A2. Regression Results for Logit Model Estimation of Binary Outcomes

\begin{tabular}{|cccc}
\multicolumn{2}{c}{$\begin{array}{c}\text { Willingness to attend } \\
\text { meeting }\end{array}$} & \multicolumn{2}{c}{ Attended the Meeting } \\
\hline Basic & With & Basic & With \\
Model & Controls & Model & Controls \\
\hline
\end{tabular}

$\begin{array}{lcccc}\text { Treatments } & & & & \\ \text { Rights information } & -0.080 & -0.062 & -0.398^{*} & -0.477^{* *} \\ & (0.355) & (0.400) & (0.224) & (0.240) \\ \text { Focus on past success } & -0.114 & -0.123 & -0.076 & -0.075 \\ & (0.342) & (0.388) & (0.210) & (0.226) \\ \begin{array}{l}\text { Demonstration of } \\ \text { engagement }\end{array} & 0.381 & 0.439 & -0.405^{*} & -0.570^{* *} \\ & (0.383) & (0.433) & (0.218) & (0.235)\end{array}$

\section{Control variables}

Primary School

0.023

$-0.332$

Secondary School

$(0.793)$

$(0.375)$

$-0.462$

$-0.060$

(0.776)

$(0.377)$

Some tertiary

$-0.399$

$-0.171$

$(0.878)$

(0.450)

Advanced Tertiary

$-0.521$

$-0.473$

$(0.844)$

(0.445)

Age

$0.027 *$

0.002

$(0.016)$

(0.008)

Gender

$-0.088$

$-0.065$

$(0.300)$

(0.176)

Location

$-0.108$

$-0.113$

$(0.301)$

(0.174)

Constant

$2.337 * * * \quad 1.988^{* *}$

$-0.632 * * *$

$-0.229$

$(0.254)$

(1.010)

(0.151)

(0.514)

Observations
Standard errors in parentheses

808

672

808

672

${ }^{* * *} \mathrm{p}<0.01,{ }^{* *} \mathrm{p}<0.05,{ }^{*} \mathrm{p}<0.1$ 


\section{Appendix 5: Minimum Detectable Effect Sizes}

Table A3. Minimum Detectable Effect Sizes for Each Outcome in Different Units

\begin{tabular}{lcccc} 
& \multicolumn{2}{c}{ Primary Outcomes } & \multicolumn{2}{c}{ Secondary Outcomes } \\
\cline { 2 - 5 } & $\begin{array}{l}\text { Attend the } \\
\text { meeting }\end{array}$ & $\begin{array}{l}\text { Political } \\
\text { Attention }\end{array}$ & $\begin{array}{l}\text { Willingness } \\
\text { to attend } \\
\text { meeting }\end{array}$ & $\begin{array}{l}\text { Pre-political } \\
\text { attention }\end{array}$ \\
\hline MDE (Units) & $11.75 \%$ & 0.306 & $7.10 \%$ & 0.322 \\
MDE (pp) & $11.75 \%$ & $6.13 \%$ & $7.10 \%$ & $6.44 \%$ \\
MDE (\% change) & $33.86 \%$ & $11.90 \%$ & $7.79 \%$ & $12.57 \%$ \\
\hline $\begin{array}{l}\text { MDE calculated assuming successful individual random assignment, excluding covariates; power }=0.8 ; \text { alpha }=0.05 . \\
\% \text { change in row 3 is relative to control group mean }\end{array}$
\end{tabular}

Appendix 6: Results of pairwise comparisons between treatment conditions.

Table A4. Pairwise Comparisons for Primary Outcomes

\begin{tabular}{|c|c|c|c|c|}
\hline & & $\begin{array}{c}\text { T-test - } \\
\text { Difference }\end{array}$ & $\begin{array}{l}\text { T-test p- } \\
\text { value }\end{array}$ & $\begin{array}{l}\text { Wald test } p \text { - } \\
\text { value }\end{array}$ \\
\hline \multirow{3}{*}{ 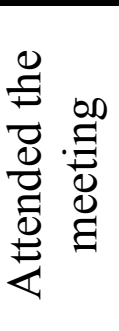 } & $\begin{array}{c}\text { Difference } \\
\text { (2)-(1) }\end{array}$ & 0.067 & 0.142 & 0.14 \\
\hline & $\begin{array}{c}\text { Difference } \\
\text { (3)-(1) }\end{array}$ & -0.001 & 0.978 & 0.977 \\
\hline & $\begin{array}{c}\text { Difference } \\
\text { (3)-(2) }\end{array}$ & -0.068 & 0.125 & 0.123 \\
\hline \multirow{3}{*}{ : } & $\begin{array}{l}\text { Difference } \\
\text { (2)-(1) }\end{array}$ & -0.094 & 0.453 & 0.447 \\
\hline & $\begin{array}{c}\text { Difference } \\
\text { (3)-(1) }\end{array}$ & -0.121 & 0.333 & 0.343 \\
\hline & $\begin{array}{l}\text { Difference } \\
\text { (3)-(2) }\end{array}$ & -0.028 & 0.821 & 0.823 \\
\hline
\end{tabular}

The comparisons above in columns 1 and 2 represent results from simple comparisons of means. Column 3 represents a Wald test for the equivalence of the respective coefficients in the primary regression model.

Intervention numbers are as follows: $1==$ Rights information, $2==$ Focus on past success, $3==$ Demonstration of engagement.

Stars denote statistical significance as follows: $* * * \mathrm{p}<0.01, * * \mathrm{p}<0.05,{ }^{*} \mathrm{p}<0.1$ 
Table A5. Pairwise Comparisons for Secondary Outcomes

\begin{tabular}{|c|c|c|c|c|}
\hline & & $\begin{array}{c}\text { T-test - } \\
\text { Difference }\end{array}$ & $\begin{array}{l}\text { T-test p- } \\
\text { value }\end{array}$ & $\begin{array}{c}\text { Wald test } \\
\text { p-value }\end{array}$ \\
\hline \multirow{3}{*}{ 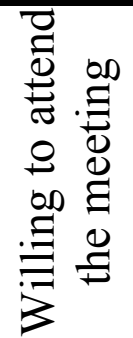 } & $\begin{array}{c}\text { Difference } \\
\text { (2)-(1) }\end{array}$ & -0.003 & 0.916 & 0.921 \\
\hline & $\begin{array}{c}\text { Difference } \\
\text { (3)-(1) }\end{array}$ & 0.032 & 0.242 & 0.225 \\
\hline & $\begin{array}{c}\text { Difference } \\
\text { (3)-(2) }\end{array}$ & 0.036 & 0.188 & 0.174 \\
\hline \multirow{3}{*}{ 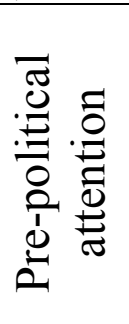 } & $\begin{array}{c}\text { Difference } \\
\text { (2)-(1) }\end{array}$ & -0.026 & 0.834 & 0.835 \\
\hline & $\begin{array}{c}\text { Difference } \\
\text { (3)-(1) }\end{array}$ & -0.325 & $0.01 * *$ & $0.008 * * *$ \\
\hline & $\begin{array}{c}\text { Difference } \\
\text { (3)-(2) }\end{array}$ & -0.299 & $0.015 * *$ & $0.015^{* *}$ \\
\hline
\end{tabular}

The comparisons above in columns 1 and 2 represent results from simple comparisons of means. Column 3 represents a Wald test for the equivalence of the respective coefficiencts in the primary regression model.

Intervention numbers are as follows: $1==$ Rights information, $2==$ Focus on past success, $3==$ Demonstration of engagement.

Stars denote statistical significance as follows: $* * * \mathrm{p}<0.01,{ }^{* *} \mathrm{p}<0.05,{ }^{*} \mathrm{p}<0.1$

\section{Appendix 7: Heterogeneous Effects Analysis}

Table A6. Regression analysis for heterogeneous effects by location

\begin{tabular}{cccc} 
Primary Outcomes & \multicolumn{2}{c}{ Secondary Outcomes } \\
\hline Attended & & Willingness & $\begin{array}{c}\text { Pre- } \\
\text { the }\end{array}$ \\
Peeting & Attention & to attend & political \\
meeting & attention
\end{tabular}

\section{Treatments}

$\begin{array}{lcccc}\text { Rights information } & -0.104 & -0.099 & -0.039 & -0.033 \\ & (0.084) & (0.208) & (0.049) & (0.202) \\ \text { Focus on past success } & -0.047 & -0.068 & -0.027 & 0.131 \\ & (0.080) & (0.201) & (0.047) & (0.195) \\ \text { Demonstration of engagement } & -0.200^{* *} & -0.081 & -0.014 & -0.405^{* *} \\ & (0.079) & (0.196) & (0.046) & (0.190)\end{array}$

\section{Interactions}

$\begin{array}{lllll}\text { Rights information x Kabale } & 0.004 & -0.146 & 0.058 & 0.490^{*}\end{array}$ 


\begin{tabular}{lcccc} 
& $(0.107)$ & $(0.266)$ & $(0.062)$ & $(0.258)$ \\
Focus on past success x & 0.052 & -0.186 & 0.027 & 0.246 \\
Kabale & $(0.104)$ & $(0.260)$ & $(0.061)$ & $(0.253)$ \\
Demonstration of engagement & 0.135 & -0.356 & 0.071 & $0.460 *$ \\
x Kabale & $(0.103)$ & $(0.258)$ & $(0.060)$ & $(0.250)$ \\
\hline
\end{tabular}

Robust standard errors in parentheses $* * * \mathrm{p}<0.01, * * \mathrm{p}<0.05,{ }^{*} \mathrm{p}<0.1$

Controls for location, age, gender, session order and education included but not reported.

Table A7. Regression analysis for heterogeneous effects by age

\begin{tabular}{cccc} 
Primary Outcomes & \multicolumn{2}{c}{ Secondary Outcomes } \\
\hline $\begin{array}{c}\text { Attended } \\
\text { the }\end{array}$ & $\begin{array}{c}\text { Political } \\
\text { Willingness }\end{array}$ & $\begin{array}{c}\text { Pre- } \\
\text { to attend } \\
\text { meeting }\end{array}$ & $\begin{array}{c}\text { political } \\
\text { attention }\end{array}$ \\
Meeting & Attention & meeting
\end{tabular}

\section{Treatments}

Rights information

$\begin{array}{lcccc} & -0.250 & 0.006 & -0.010 & 0.127 \\ \text { Focus on past success } & (0.153) & (0.383) & (0.090) & (0.375) \\ & 0.128 & 0.337 & 0.054 & -0.201 \\ \text { Demonstration of engagement } & (0.160) & (0.400) & (0.093) & (0.392) \\ & -0.317^{* *} & 0.203 & 0.103 & -0.365 \\ & (0.159) & (0.399) & (0.093) & (0.389)\end{array}$

Interactions

\begin{tabular}{lcccc} 
Rights information x Age & 0.005 & -0.006 & 0.000 & 0.004 \\
& $(0.004)$ & $(0.011)$ & $(0.003)$ & $(0.011)$ \\
Focus on past success x Age & -0.004 & -0.016 & -0.002 & 0.015 \\
& $(0.005)$ & $(0.012)$ & $(0.003)$ & $(0.011)$ \\
Demonstration of engagement & 0.006 & -0.015 & -0.002 & 0.007 \\
x Age & $(0.005)$ & $(0.012)$ & $(0.003)$ & $(0.011)$ \\
\hline
\end{tabular}

Robust standard errors in parentheses $* * * \mathrm{p}<0.01, * * \mathrm{p}<0.05,{ }^{*} \mathrm{p}<0.1$

Controls for location, age, gender, session order and education included but not reported. 
Table A8. Regression analysis for heterogeneous effects by gender

\begin{tabular}{|c|c|c|c|}
\hline Primar & comes & \multicolumn{2}{|c|}{ Secondary Outcomes } \\
\hline Attended & $\mathrm{Po}$ & Willingness & $\begin{array}{c}\text { Pre- } \\
\text { nolitical }\end{array}$ \\
\hline Meeting & Attention & meeting & attention \\
\hline
\end{tabular}

\section{Treatments}

$\begin{array}{lcccc}\text { Rights information } & -0.043 & -0.421^{* *} & -0.059 & 0.272 \\ & (0.079) & (0.198) & (0.046) & (0.193) \\ \text { Focus on past success } & 0.020 & -0.309 & 0.008 & 0.163 \\ & (0.081) & (0.203) & (0.047) & (0.199) \\ \text { Demonstration of engagement } & -0.181^{* *} & -0.394^{* *} & 0.004 & -0.240 \\ & (0.078) & (0.196) & (0.046) & (0.191)\end{array}$

\section{Interactions}

\begin{tabular}{lcccc} 
Rights information x Female & -0.105 & 0.411 & 0.098 & -0.015 \\
& $(0.105)$ & $(0.262)$ & $(0.061)$ & $(0.255)$ \\
Focus on past success X & -0.060 & 0.221 & -0.027 & 0.193 \\
Female & $(0.104)$ & $(0.262)$ & $(0.061)$ & $(0.255)$ \\
Demonstration of engagement & 0.096 & 0.186 & 0.041 & 0.182 \\
x Female & $(0.103)$ & $(0.257)$ & $(0.060)$ & $(0.250)$ \\
\hline
\end{tabular}

Robust standard errors in parentheses $* * * \mathrm{p}<0.01,{ }^{*} \mathrm{p}<0.05,{ }^{*} \mathrm{p}<0.1$

Controls for location, age, gender, session order and education included but not reported. 
Table A9. Regression analysis for heterogeneous effects by session order

\begin{tabular}{|c|c|c|c|}
\hline Primar & comes & \multicolumn{2}{|c|}{ Secondary Outcomes } \\
\hline Attended & $\mathrm{Po}$ & Willingness & $\begin{array}{c}\text { Pre- } \\
\text { nolitical }\end{array}$ \\
\hline Meeting & Attention & meeting & attention \\
\hline
\end{tabular}

\section{Treatments}

Rights information

$\begin{array}{lccc}-0.128 & 0.058 & 0.045 & 0.380 \\ (0.117) & (0.292) & (0.068) & (0.285) \\ -0.029 & 0.104 & 0.057 & 0.310 \\ (0.120) & (0.299) & (0.070) & (0.293) \\ -0.050 & 0.179 & 0.036 & 0.089 \\ (0.120) & (0.298) & (0.070) & (0.291)\end{array}$

\section{Interactions}

Rights information x Session

$$
0.003
$$

$-0.030$

$-0.006$

$-0.014$

order

$$
\text { (0.013) }
$$

$(0.033)$

$(0.008)$

(0.032)

Focus on past success $\mathrm{x}$

$0.002 \quad-0.035$

$-0.008$

$-0.003$

Session order

$(0.013) \quad(0.033)$

(0.008)

(0.032)

Demonstration of engagement

$-0.009-0.057 *$

$-0.001$

$-0.027$

$\mathrm{x}$ Session order

$(0.013) \quad(0.033)$

$(0.008)$

$(0.032)$

Robust standard errors in parentheses $* * * \mathrm{p}<0.01, * * \mathrm{p}<0.05, * \mathrm{p}<0.1$

Controls for location, age, gender, session order and education included but not reported. 